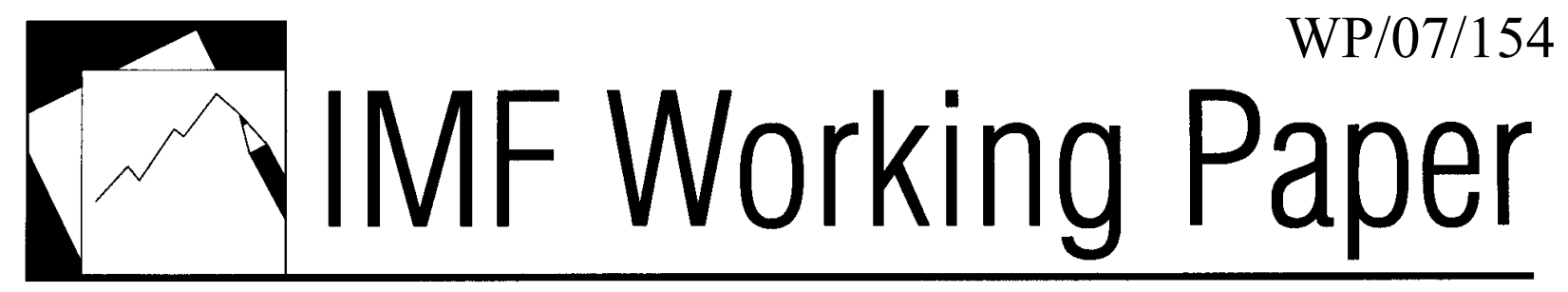

\title{
Welfare Gains from Financial Liberalization
}

Robert M. Townsend and Kenichi Ueda 



\title{
IMF Working Paper
}

\author{
Research Department
}

\section{Welfare Gains from Financial Liberalization}

\section{Prepared by Robert M. Townsend and Kenichi Ueda ${ }^{1}$}

Authorized for distribution by Stijn Claessens

July 2007

\begin{abstract}
This Working Paper should not be reported as representing the views of the IMF.

The views expressed in this Working Paper are those of the author(s) and do not necessarily represent those of the IMF or IMF policy. Working Papers describe research in progress by the author(s) and are published to elicit comments and to further debate.

Financial liberalization has been a controversial issue as there is little empirical evidence for its positive effects on economic growth. However, we find sizable welfare gains, 1 to 28 percent of permanent consumption though, consistent with the literature, the gain in the economic growth is ambiguous, -0.2 to 0.7 percent. We apply a canonical growth model with endogenous financial deepening to Thailand, 1976-96. As effective bank transaction costs decline, more people take advantage of financial services. We estimate the gains by comparing model simulations under the historical episode of financial liberalization to those under a hypothetical continuation of financial repression.
\end{abstract}

JEL Classification Numbers: G28, O16, O17

Keywords: financial liberalization, welfare gain, financial deepening, economic growth

Author’s E-Mail Address: rtownsen@uchicago.edu, kueda@imf.org

\footnotetext{
${ }^{1}$ Robert M. Townsend is a professor at the University of Chicago and a consultant at the Federal Reserve Bank of Chicago. Kenichi Ueda is an economist at the International Monetary Fund. Financial support from the NSF and NICHD is gratefully acknowledged. We thank the National Statistics Office of Thailand for permission to use the SES data. We want to acknowledge comments from Fernando Alvarez, Dan Bernhardt, Paco Buera, Stijn Claessens, John Cochrane, Xavi Giné, Hyeok Jeong, Aart Kraay, Stefan Krasa, Bob Lucas, Alex Monge, Richard Rogerson, and Nancy Stokey, and the participants of the SED conference at Vancouver, Econometric Society Winter Meeting at Chicago, and seminars at the IMF, the World Bank, and the Universities of Chicago and Illinois at Urbana-Champaign.
} 


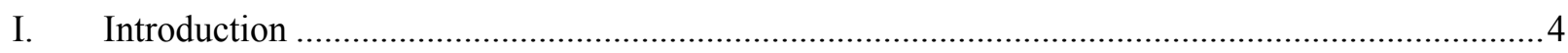

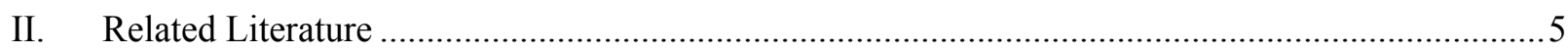

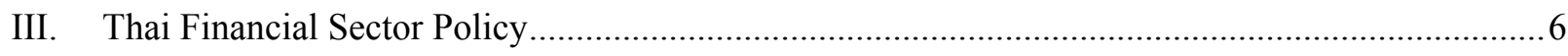

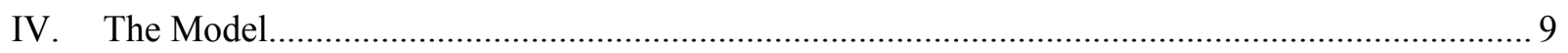

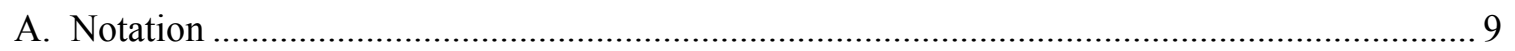

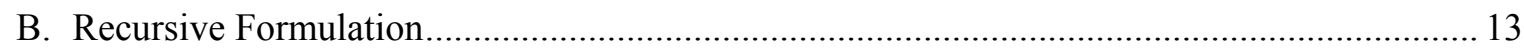

C. Solutions of Value Functions and Policies ........................................................................... 13

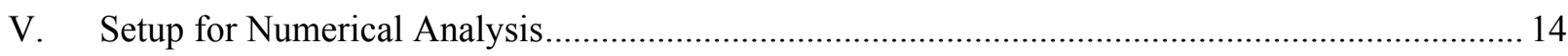

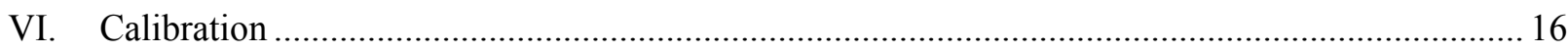

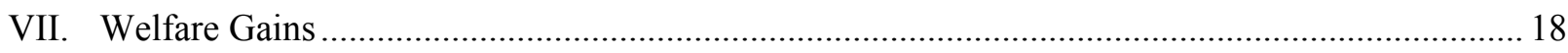

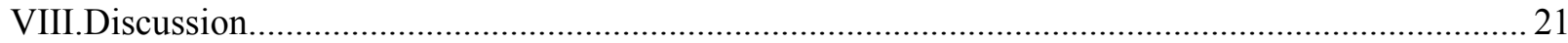

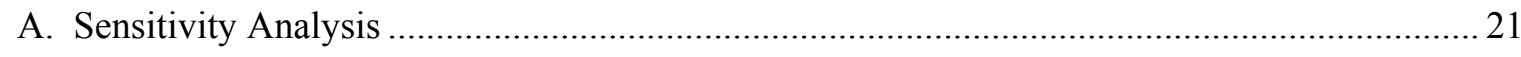

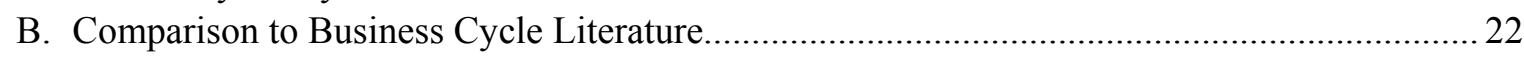

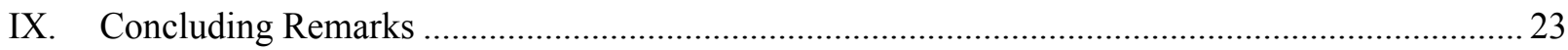

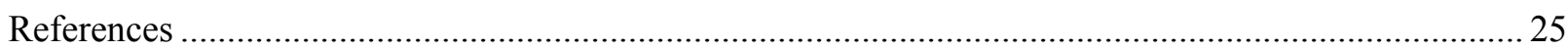

Tables

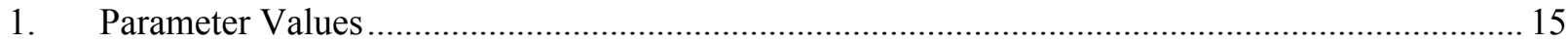

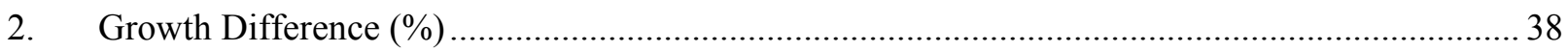

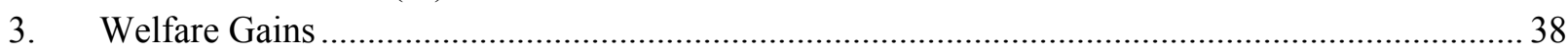

4. Sensitivity Analysis: Variable Cost Reduction..................................................................... 39

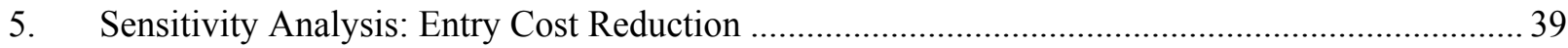

\section{Figures}

1. Financial Liberalization and Gini of Tobin's Q............................................................. 28

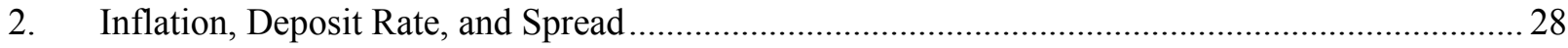

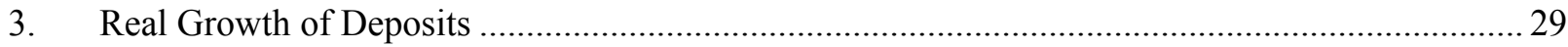

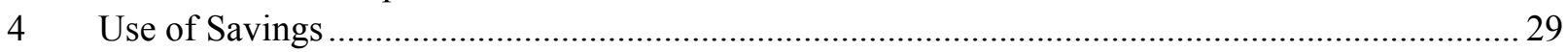

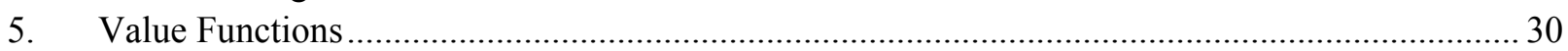

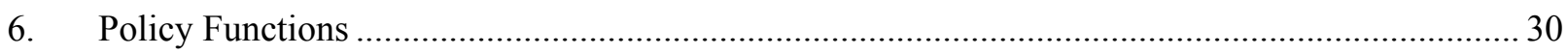

7. Benchmark

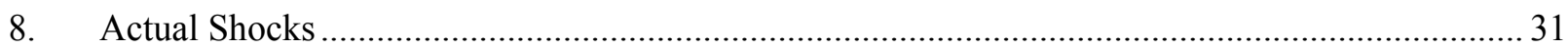

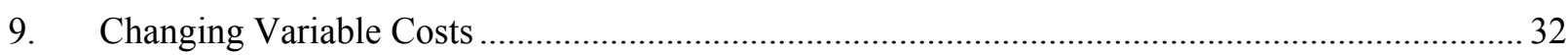

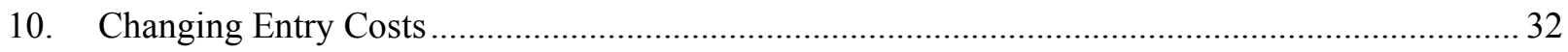

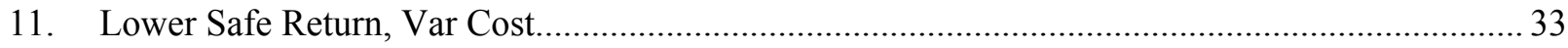




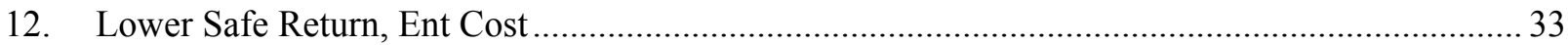

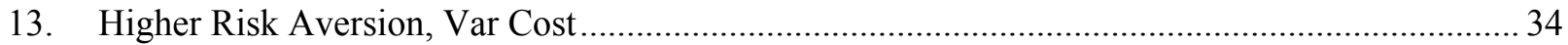

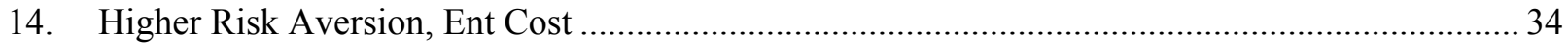

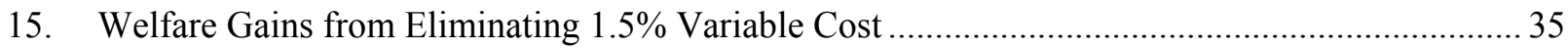

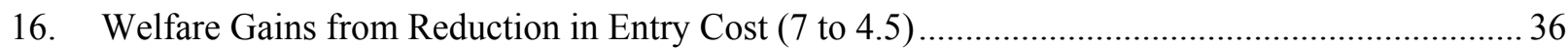

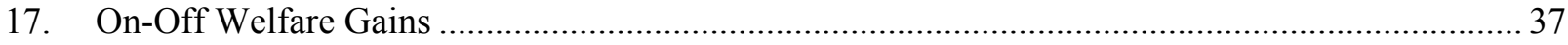

Appendix

I. Closed-Form Solutions of Welfare Gains for Participants ...................................................... 40 


\section{INTRODUCTION}

Financial liberalization has been a controversial issue, ${ }^{2}$ as there is little empirical support for positive effects on growth in savings, investment, or GDP. Bandiera and others (2000) show, in a sample of eight developing countries, that financial liberalization is not associated with an increase in savings. Jayaratne and Strahan (1996) find that deregulation of interstate bank branches in the United States did not increase the volume of bank lending. Sancak (2002) finds similarly little effects in Turkey.

Yet, these findings are not inconsistent with theory. Indeed, theoretical predictions are mixed and thus it seems unwise to evaluate the success of a financial liberalization based on its effect on growth in savings, investment, and GDP. In McKinnon (1973) and Shaw (1973), the removal of interest rate ceilings were imagined to generate higher interest rates, leading to higher savings and investments. But theoretically, the relative size of income and substitution effects from higher interest rates are ambiguous. Likewise, better insurance against future risks could bring higher growth as this enables entrepreneurs to seek higher-risk, higher-return projects (Obstfeld, 1994). But, better insurance arrangements may decrease the need for savings for precautionary motives (Devereux and Smith, 1994) and result in lower investment and GDP growth.

Still, these theories do predict unambiguous increase in welfare. Unambiguous effects may also appear as an increase in efficiency in allocating capital, which some papers support. ${ }^{3}$ But, without a utility or overall objective function, it would be difficult to judge if these efficiency gains are large, small, or worth the political costs.

Here, we compute welfare gains from a financial liberalization based on a canonical model with an explicit utility function. Unlike a hypothetical experiment comparing an economy with a financial sector to one without, we compute the welfare gains from a financial liberalization in a model exhibiting endogenous financial deepening along the transitional path in economic growth. The financial sector is endowed with two functions, risk sharing and an efficiency gain in production, as these are typically considered to be the key functions of banks. The financial sector in the model requires both fixed costs of entry and variable costs for operations, and these create endogenous movements into intermediation, facilitated by high wealth. Financial liberalization is layered on top of this and is defined as a decline in those costs. It removes distortions and accelerates financial deepening.

In a calibration exercise, allowing for potential factors which affect economic growth, we show that the model prediction under actual financial sector policies trace the historical movements in the GDP growth rates and financial deepening. For this, we use actual data and historical regulatory material from a specific country, Thailand, in the phase of rapid economic growth and financial deepening,

\footnotetext{
${ }^{2}$ We focus on liberalization of domestic financial activities, not capital account liberalization which allow international transactions.

${ }^{3}$ Abiad, Oomes, and Ueda (2004) measure efficiency in allocating of capital across firms using a Gini inequality index of Tobin's Q. They show that it falls with financial liberalization in five developing countries. Also, using the U.S. branch deregulation episode, Acharya, Imbs, and Sturgess (2006) show that the industry structure of each state moved towards mean-variance efficiency frontier after the deregulation. Note that these empirical studies show that market-based allocation of capital appears more efficient with financial liberalization, in contrast to Hellmann, Murdock, and Stiglitz (1996), which argues in theory in the economy with private information that government intervention in the financial sector may make a second best allocation closer to a first best allocation.
} 
namely 1976-1996. We specify the preference and technology parameters as in Townsend and Ueda (2006), simulate the model, and compare with the actual historical path. The model is consistent with the sequence of historical events, when we treat the government's share in new bank lending as a policy distortion: an acute repression starting in early 1980 ending with liberalization in 1987-89.

We also simulate the model without the liberalization and compare the results. We find sizable welfare gains, though the model predicts, consistent with the literature, the gain in the economic growth is ambiguous. Specifically, our estimates of the welfare gains from this specific financial liberalization episode in Thailand turn out to be large, from a 1 percent to 28 percent increase in permanent consumption, though the impact on economic growth is mixed, -0.2 to 0.7 percent in the subsequent 10 year term.

The paper proceeds as follows. Section II surveys a related literature. Section III describes Thai financial sector policy in the sample period. Section IV describes the model, and Section V explains how we conduct simulations. Section VI reports results of the simulation exercise. Section VII calculates the welfare gains. Section VIII discuss results with sensitivity analysis. Finally, Section IX concludes.

\section{RElATED Literature}

A closely related literature studies effects of financial deepening, typically measured by M2, private credit, and market capitalization as a ratio to GDP. For example, King and Levine (1993) and Levine, Loayza, and Beck (2000) show in their regression studies that financial depth is associated positively with subsequent economic growth. Beck, Levine, and Loayza (2000) find that financial deepening affects growth through an increase in total factor productivity.

However, Townsend and Ueda (2006) point out that regressions may not pin down a causal link between financial deepening and its effect. First, financial deepening is an endogenous variable, an aggregation of individual's decision. ${ }^{4}$ See the theoretical literature of financial deepening and growth, for example, Greenwood and Jovanovic (1990), Greenwood and Smith (1996), and Acemoglu and Zillibotti (1998). Second, in all these models, financial deepening occurs jointly with economic growth and is a transitional phenomenon, before convergence to a long-run steady state. Transitional dynamics creates a complex relationship and the resulting macro data are not typically stationary and ergodic. This force researchers to view the entire history as one sample draw. Instead, if we conduct a panel regression of, say, economic growth onto financial deepening on data generated from models of transitions, spurious effects can arise.

Focusing on financial liberalization somewhat mitigates the problem, as financial repression and liberalization are the domain of government policy, which can be regarded as exogenous to private agents. Still, the same problem arises when a financial sector policy affects endogenous financial deepening in transitions. This problem would remain even with a micro level study, for example, difference-in-difference estimation using consumption data of those who use financial services and those who do not. This is because, as we discuss in detail below, theories of endogenous financial

\footnotetext{
${ }^{4}$ By looking at the industry-level implication, Rajan and Zingales (1998) eliminate possible omitted variable bias arising from the endogeneity problem in cross-country studies.
} 
deepening predict that any policy change that affects financial sector performance or changes entry barriers will alter the behavior of those who are not yet using financial services.

Since economic agents in the model use discounted expected utility to make their decisions on financial participation and savings, we as researchers should use the same utility criterion to assess the impact of the policy change. A similar methodology can be found in the literature on the welfare gains from eliminating macro business cycles_-see Lucas (1987) and many papers on international risk sharing, reviewed by van Wincoop (1999) and Prasad and others (2003). Reported welfare gains in the business cycle literature are usually small; several papers report less than a 0.5 percent increase in permanent consumption. However, developing countries with higher fluctuations may benefit more from smoothing GDP volatilities (Obstfeld, 1995). Finally, to our knowledge, few calibration studies have examined the welfare gains from a within-country, domestic financial liberalization. ${ }^{5}$

We propose to evaluate financial liberalization in the context of a model with a financial sector both before and after the liberalization. A financial sector is typically present in actual economies before liberalization and would hardly be perfect after liberalization. A related but quite important aspect is that financial sector development can be occurring endogenously, whether or not the exogenous financial sector policies are implemented. Our methodology contrasts to that of the welfare cost of business cycle literature, in which the conceptual experiments are on-off experiments, comparing the economy with perfect smoothing of business cycle to one without. If we adopted a similar strategy, we would answer only the following question: what would happen if perfect financial arrangements were introduced suddenly? This question is extreme, if not unrealistic, like comparing an economy without money to one with money to impute the effects of monetary policy on business cycles—of course, every researcher evaluates monetary policy in the context of an economic model with money.

\section{Thai Financial Sector Policy}

Rapid economic growth and financial deepening characterize Thai economy from 1976 to 96 . As dashed lines of Figure 7 shows, growth and financial deepening ${ }^{6}$ stalled somewhat between 1980 and 1986 and both then suddenly rose together in 1987. Casual observation might suggest a positive link between the financial deepening and growth. Before analyzing this formally, we would like to review the financial sector policies in Thailand for this sample period.

Laws and regulations do not seem to change much in 1980s. The standard de jure documentation of financial liberalization consists of a documented chronology of changes in laws and regulations. The dashed line of Figure 1 shows a financial liberalization index by Abiad and Mody (2005) for Thailand. ${ }^{7}$ Evidently, by this standard, Thailand did not liberalize substantially until 1989, except for a small improvement in 1979. Note that there is some discretion in defining events when constructing these indices: a Bank of Thailand document suggests changes may have begun as early

\footnotetext{
${ }^{5}$ Broner and Ventura (2005) study theoretical interactions between domestic financial deepening and capital account liberalization. They show that capital account liberalization might worsen welfare by reducing domestic financial integration, when agents are assumed to breach financial contracts each other at the time of sovereign defaults.

${ }^{6}$ Our financial deepening measure is fraction of households which have bank accounts.

${ }^{7}$ The index is normalized to one. They create an index of de jure regulation out of six categories: interest rate controls, directed credit, entry restrictions, privatizations, international transactions, and prudential regulations.
} 
as in 1986, including more liberalized bank branching. Also, Bekaert, Harvey, and Lundblad (2005) identify 1987 as the year that Thailand opened its equity market investments to foreigners.

However, actual, de facto deregulation may be distinct. For example, Bergloff and Classens (2003) argue that laws and regulations regarding corporate governance may be implemented with lags. More generally, one can create efficiency indicators from micro data and track improvements. For example, using a Gini coefficient measure of dispersion in Tobin's Q of listed companies, Abiad, Oomes and Ueda (2004) show that there are substantial improvements for Thailand dating from 1987 (see the solid line of Figure 1).

It is important to note also that de jure changes and de facto changes need not move together. Hoshi and Kashyap (1999) argue that deregulation of the corporate bond market in Japan in the late 1980s, without deregulation of banking sector, made banks lose their best client firms. Banks then expanded loans to relatively unknown clients with more reliance on real estate as collateral, a source of the bubble with the eventual problems of the 1990s.

Likewise, there may be de facto financial repression even though laws and regulation do not change. Changes in economic conditions can cause a problem, sometimes exacerbated by subsequent policy change. By this standard, the degree of de facto financial repression in Thailand appears large for the early to mid 1980s. We use a study conducted by the International Monetary Fund (Robinson and others, 1991), with additional data, to identify three main features that likely created a large cost of using financial services.

First, in 1979 to 1981, as nominal interest rate controls remained in effect and inflation suddenly rose (due to an oil shock), the real interest rate became negative - the nominal deposit rate was around 12 percent, while the inflation rate hit 20 percent (see Figure 2). The negative deposit rate clearly deterred households from making new deposits. As Figure 3 shows, real growth of demand deposits was quite low for $1979-1985 .^{8}$ As for the loan side, note that low real loan rates would have allowed inefficient firms to continue.

Second, and as a consequence of low deposit growth and the funding of inefficient firms, a financial crisis started in 1983. This eventually spread to one third of all financial institutions (a quarter of total financial assets). ${ }^{9}$ The Bank of Thailand and the Ministry of Finance intervened, injecting capital into financial institutions, in some cases taking over management by acquiring shares - most shares are eventually sold off to the original owners by the end of 1980s. The government-based allocation of capital was not likely as efficient as a market-based allocation and we model this below. Note that if the government had not bailed out banks, the Thai financial sector might have performed even worse. However, the main cause of the crisis appeared to be the interest rate controls, combined

\footnotetext{
${ }^{8}$ Total deposit growth was low only up to 1982 and then turned higher. This difference in movements may reflect a differential change in the interest rates of two types of deposits, basically, checking and savings accounts. Note, however, that opening of new bank accounts should be more in line with the growth in the demand deposits, as the new customers are likely to be less wealthy and save relatively more in the demand deposit accounts than the less liquid deposit accounts. Evidently, potential new depositors are more sensitive to negative interest rates.

${ }^{9}$ Thus, the financial crisis in Thailand in 1980s appears to have been caused by repressive financial sector regulations combined with inflationary shocks. This contrasts to some recent studies (e.g., Kaminsky and Schmukler (2003) and Ranciere, Tornell, and Westermann (2006)), who argue that financial liberalization, though beneficial in the long run, is a culprit in financial crises.
} 
with the oil shock. Thus, we regard the subsequent bailout policies as an integral part of the de facto financial repression, even though it was unintentional.

Third, due to the recession and the bailout of banks, in fiscal years 1979/80 to 1987/88, the central government recorded a fiscal deficit, sometimes large, more than 5 percent of GDP. ${ }^{10}$ Those deficits were financed mainly by the domestic financial system. As a result, banks lent a larger sum to the government, almost as much as to the private sector (see the solid line of Figure 4), especially from 1984 to 1986. In contrast, the government's share in new bank lending eventually became negative, by 1990. Accordingly, private capital formation out of national savings was low from 1982 to 1987 , but this then increased dramatically (see the dashed line in Figure 4). ${ }^{11}$

In sum, de facto measures seem to capture Thai financial sector policies better than de jure measures. By any of these measures, the broad implications look the same: inefficiency of the financial sector seems to have increased dramatically in the early 1980s, then declined in the mid to late 1980s. Equivalently, the cost using the financial sector increased and then declined.

These de facto policy changes are difficult to quantify as they are of multiple dimensions and often complex. However, to make progress, we need to simplify: We pick the government share in new bank lending as our de facto measure for calibration in the model simulation. This measure shows clearly that savings were used less productively in much of 1980s. On the other hand, we see some flaws in other measures. Reported interest rates might not reflect the true rates, because under controlled interest rates, nonprice competition may occur in various forms such as gifts to depositors and bribes for loan officers. Deposit amounts are too closely linked to our financial deepening measure, the fraction of households having a bank accounts.

Finally, de facto measures appear to have been related to the variable costs; they were not directly associated with bank entry or branch openings but rather with efficiency in allocating capital to profitable projects. Hence, we focus on movements in variable costs of financial intermediation. But as a robustness check we also look at the extensive margin, that is, higher fixed costs of joining the financial system.

\footnotetext{
${ }^{10}$ As the capital expenditures were always around $1 / 5$ of total fiscal expenditure for the sample periods (Robinson and others, 1991), the increased fiscal expenditures do not seem linked to a more active public capital spending (which could otherwise have contributed a higher growth from late 1980s).

${ }^{11}$ Data for Figures 2-4 are from various sources. Based on IMF's International Financial Statistics (IFS), on-line version for October 2006 issue, the government share in new bank lending is calculated as increase in claims on central government and claims on public nonfinancial corporation divided by the increase of sum of claims on central government, claims on public nonfinancial corporation, and claims on private sector. IFS also provides data for total deposits, which is the sum of demand deposits and time, savings, and foreign currency deposits. Growth rates of deposits are adjusted for inflation. Inflation is calculated from the consumer price index in the World Economic Outlook Database, which also provides the data for gross capital formation and gross domestic product. Deposit rate and lending rate are from the World Bank Development Indicators. Note that there are changes in statistical definitions for deposits and banks' claims in 1976, so that those numbers before and after 1976 are not perfectly comparable.
} 


\section{THE MODEL}

\section{A. Notation}

The model is a modified version of a simple, tractable growth model with a financial sector, the one used in Townsend and Ueda's (2006) calibration study, following the tradition of Greenwood and Jovanovic (1990) and Townsend (1983). Specifically, Townsend and Ueda (2006) conducted a model-based simulation study of Thailand 1976-1996 and found some evidence in transitions towards a long-run steady state for a complex interlinkage among finance, inequality, and growth. However, they were unable to generate some of the more salient movements in Thai economy, namely the sudden surge in financial sector participation and economic growth in the middle to late 1980 's. Here, we interpret the relatively abrupt change as the consequence of a policy change, exogenous to private agents. We therefore modify the model to include a government sector explicitly.

There is a continuum of agents, consumer-cum-entrepreneurs, as if with names indexed on the interval $[0,1]$. At the beginning of each period, they start with their assets $k_{t}$. After they consume $c_{t}$, they use savings $s_{t}$ to engage in productive activities.

An individual can engage in two types of productive activities: a safe but low-return occupation (e.g., agriculture) and high-risk high-return business. Safe projects are assumed to return $\delta$ and risky businesses are assumed to return $\eta_{t}=\theta_{t}+\epsilon_{t}$, where $\theta_{t} \in \Theta$ is an aggregate shock, common to all businesses, something which clearly moves GDP growth, and $\epsilon_{t} \in \mathcal{E}$ is an idiosyncratic shock, different among risky businesses. The cumulative distribution functions are denoted by $F\left(\theta_{t}\right)$ and $H\left(\eta_{t}\right)$ for the aggregate shock and the sum of the aggregate and idiosyncratic shocks, respectively. An individual does not have to stick to the same projects over time, and she can choose portion $\phi_{t} \in[0,1]$ of her savings $s_{t}$ to invest in high-risk high-return projects. Savings $s_{t}$ is also endogenous. In summary, those who are not using financial services accumulate assets according to ${ }^{12}$

$$
k_{t+1}=\left(\phi_{t}\left(\theta_{t}+\epsilon_{t}\right)+\left(1-\phi_{t}\right) \delta\right) s_{t} .
$$

A financial institution provides two services to its customers in this simple model. First, a financial institution offers insurance for idiosyncratic shocks, essentially pooling ex post returns as in a mutual fund. ${ }^{13}$ Second, a financial institution raises productivity of a project. This is in line with several theories on a bank's role as efficiency enhancement; for example, by preventing moral hazard (Diamond, 1984) or internalizing an externality (Ueda, 2006). Financial services, however, require a

\footnotetext{
${ }^{12}$ To have a simple analytical expressions for participants' value functions and welfare gains, defined later, the model assumes 100 percent depreciation of wealth, so that the income and the wealth are the same.

${ }^{13}$ We note that the perfect insurance for those who participate financial system is an extreme assumption. However, Alem and Townsend (2007), using a Thai household survey data collected by Townsend and others (1997), indicate that some financial institutions such as the Bank of Agriculture and Agricultural Cooperatives (BAAC) come close to meeting this standard. Also, Townsend and Yaron (2001) shows that the contingency repayment plan of the BAAC is an institutional mechanism which potentially insures income risks of farmers quite well. Still, the literature needs more research on how much insurance people can obtain by joining a financial system.
} 
one-time cost $q>0$ to start using them and a per-period cost $(1-\gamma) \in[0,1]$ proportional to the savings amount. These costs are intrinsic, so that no one can claim these resources once spent. ${ }^{14}$

On the efficiency gains we simply assume, following Greenwood and Jovanovic (1990), that banks have an informational advantage in the selection of projects. Specifically, when people apply for loans, banks gather information on the true aggregate shock and advise applicants if they should stay in the relatively safe occupation or engage in the high-risk high-return business. ${ }^{15}$ To simplify the analysis, we assume that banks are able to infer the true underlying shock. As such, once screened, the return from a project for a household becomes $R\left(\theta_{t}\right)+\epsilon_{t}$, where $R\left(\theta_{t}\right) \equiv \max \left\{\theta_{t}, \delta\right\}$.

On risk and insurance, we assume that a household puts all money on deposit but then borrows to finance a project and repays conditional on the returns. The return from a project for a household contains idiosyncratic fluctuations $R\left(\theta_{t}\right)+\epsilon_{t}$, so repayments depend on the aggregate shocks $\theta_{t}$ and the idiosyncratic shocks $\epsilon_{t}$. Thus, the overall return on savings depends only on aggregate shocks. An alternative interpretation is that a financial institution is a mutual fund; that is, households buy shares in the mutual fund (savings), and the fund invests across projects to pool idiosyncratic risks, then pays off a return contingent on the aggregate shocks only. Theoretically, as Townsend (1978) and Greenwood and Jovanovic (1990) show, competition drives banks to provide insurance for idiosyncratic shocks using loan contracts with varying repayment obligations (e.g., defaults) conditional on realized idiosyncratic shocks. However, the exact loan contract for each household depends on the total value of loans, which may be smaller than total deposits as banks also buy government bonds.

A government runs state-owned firms. Idiosyncratic shocks are again pooled by banks. The government also obtains advice from banks. Thus, returns from projects are the same as the private sector, less an additional cost $z$ due to bureaucratic inefficiency. The total return from the government-run projects is thus $(1-z) R\left(\theta_{t}\right)$, lower than the mean return of private firms. Under financial repression, a government sets the deposit and loan rates, as well as government bond yields. As the government has no intention of making profits, it sets the yield on government bond equal to the return from government-run projects. To fulfill all its financing needs, a government also sets the population average commercial loan rates equal to government bond yields, thus preempting competition from the financial sector for loans_-banks become indifferent between the government-bond holdings and the private-sector loans. In sum, the loan rate $r^{L}\left(\theta_{t}, \epsilon_{t}\right)$ is set at $(1-z) R\left(\theta_{t}\right)+\epsilon_{t}$. Again, this contract embodies insurance, as a household with a good shock repays the temporary high profit to a bank, while a household with a bad shock repays less than the average. Note that the loan rate is lower than the return from the private business, $R\left(\theta_{t}\right)+\epsilon$. The difference $z R\left(\theta_{t}\right)$ remains in hands of the consumer-cum-entrepreneurs as profit income. Through competition, the loans are allocated among households proportionally to their deposits, and banks offer a package

\footnotetext{
${ }^{14}$ Indeed in the real world, banks need to offer extra services, which are not necessary in self investment activities. Examples of variable costs include preparing accounting statements and printing deposit statements. Examples of fixed costs include building branches and checking credit history. Those costs must be charged to depositors as a result of competition and the fee structure is optimal (see Townsend $(1978,1983)$ and Greenwood and Jovanovic (1990)). In addition, depositors themselves typically pay additional costs; for example, buying a motorbike to visit a branch and traveling time to a branch.

${ }^{15}$ For example, when a Thai farmer in countryside tries to start a rubber-making business and ask a bank to provide loans, the bank, headquartered in Bangkok, would gather information on potential demand and costs, including forecasts of the international rubber price.
} 
of deposit and loan contracts to each consumer-cum-entrepreneur. ${ }^{16}$ Again, under the mutual fund interpretation, investors receive dividend income, distributed at the end of each period to the fund holders in proportion to invested funds.

As typically observed in a financial repression, and from the evidence presented earlier, both deposit and loan rates are set by the government with a generous spread, intended to provide banks with positive rents. However, an artificial spread would be easily dissipated as banks would engage in nonprice competition (e.g., gift giving). ${ }^{17}$ When both loan and deposit rates are lower than the market equilibrium rate, there is a relative shortage of deposits, hence banks would engage in nonprice competition for depositors, using all the artificial rents created by the government. As a result, the effective, net-of-transaction-cost, deposit rate $r^{D}\left(\theta_{t}\right)$ must be equal to $(1-z) R\left(\theta_{t}\right)$, the population average loan rate.

All savings $s_{t}$ are deposited in banks, but the net deposit amount is really $D_{t}=\gamma s_{t}$ after taken out costs, $(1-\gamma)$ fee. Out of this deposit $D_{t}$, banks purchase government bonds $G_{t}$ and lend out the remaining funds $L_{t}$ to firms; that is,

$$
D_{t}=L_{t}+G_{t}
$$

A household using financial services decides on savings $s_{t}$ to put in banks, considering both the interest income and profit income, as the participants' wealth evolves as: ${ }^{18}$

$$
k_{t+1}=r^{D}\left(\theta_{t}\right) D_{t}+z R\left(\theta_{t}\right) L_{t} .
$$

Using (2) and $r^{D}\left(\theta_{t}\right)=(1-z) R\left(\theta_{t}\right)$,

$$
k_{t+1}=R\left(\theta_{t}\right) D_{t}-z R\left(\theta_{t}\right) G_{t} .
$$

To simplify the formula further, we assume that the government borrows at a constant portion of aggregate deposits, $G_{t}=\alpha D_{t}$. Parameter $\alpha$ characterizes the financial regime. With this assumption, the evolution of wealth of participants can be expressed as:

$$
k_{t+1}=(1-\alpha z) R\left(\theta_{t}\right) D_{t}=(1-\alpha z) R\left(\theta_{t}\right) \gamma s_{t} .
$$

Apparently, the larger is the size of government $\alpha$ and the larger is inefficiency in government-run business $z$, the lower the overall return from savings. We define the overall return from savings as

\footnotetext{
${ }^{16}$ If profit income is not allocated in proportion to deposits, there would be cross-subsidization among households. This would be impossible in an equilibrium, as another bank would offer more profit income per deposit for those who contribute to fund the implicit subsidy.

${ }^{17}$ Another interpretation would be that the spread is retained solely by banks. Even so, for credit-union and cooperative like banks, the profits would be distributed based on deposit amounts, so the model specification would remain the same. If distinct bankers own banks, then bank profits would be consumed by the bankers. In this case, an artificial spread can be thought of as a transfer from depositors to bankers. We will discuss an implication of this interpretation later when we calculate welfare gains.

${ }^{18}$ Because an entrepreneur obtains loans based on the deposit amount in the model, she takes into account the profit income when depositing. Under the alternative, mutual fund interpretation, both the profit income and loan rate would be combined as the income of the mutual fund and then distributed to the investors.
} 
$r\left(\theta_{t}\right) \equiv \hat{\gamma} R\left(\theta_{t}\right)$ where $\hat{\gamma} \equiv(1-\alpha z) \gamma$. Wealth evolution for participants given savings $s_{t}$ can now be expressed as

$$
k_{t+1}=r\left(\theta_{t}\right) s_{t}
$$

The effective variable cost $(1-\hat{\gamma})$ combines intrinsic transactions costs $\gamma$ and institutional impediments to a country's financial sector, summarized here as parameters $\alpha$ and $z .{ }^{19}$ We can also think of the fixed entry cost $q$ as representing both intrinsic and institutional impediments, such as branch regulation. Both these costs are a key part of the policy analysis which follows.

We assume in addition that the risky asset is profitable enough to potentially attract some positive investment, that is, the expected risky return dominates the safe return, and that intermediation provides a further advantage.

\section{Assumption 1.}

$$
E\left[r\left(\theta_{t}\right)\right]>E\left[\theta_{t}\right]>\delta>0
$$

An individual chooses at date $t$ whether she uses financial service $d_{t}=1$ or not $d_{t}=0$, savings $s_{t}$, and portfolio share of risky projects $\phi_{t}$ to maximize her expected life-time utility:

$$
E_{1}\left[\sum_{t=1}^{\infty} \beta^{t-1} u\left(c_{t}\right)\right]
$$

subject to the budget constraint

$$
c_{t}=k_{t}-s_{t}-q \mathbf{1}_{d_{t}>d_{t-1}},
$$

where $\beta \in(0,1)$ denotes the consumers' discount rate and $\mathbf{1}_{d_{t}>d_{t-1}}$ denotes an indicator function, which takes value 1 if an individual joins the financial system at $t$ (i.e., $d_{t}>d_{t-1}$ ) and takes value 0 otherwise. We use the log contemporaneous utility for the most part of this paper, but we also report a sensitivity analysis using a constant relative risk aversion (CRRA) utility function $u\left(c_{t}\right)=c_{t}^{1-\sigma} /(1-\sigma)$, where $\sigma$ denotes the degree of relative risk aversion.

Note that the production function is a linear, essentially $A k$-type, technology. This assumption is a departure from neoclassical growth models but in line with so called new growth theories. ${ }^{20}$ Besides, most studies of the welfare gains from eliminating business cycles are based on simple exogenous endowment economies. An exception of the business cycle literature is Epaullard and Pommeret (2003), a simulation study based on Obstfeld (1994), an $A k$ growth model with recursive utility. Their representative macro agent invests in higher-risk and higher-return projects when risks are insured; again, this creates higher growth and, more to the point, a higher welfare gain in terms of wealth compensation. This is, however, discouraging, as the empirical literature has found few growth effects. $^{21}$

\footnotetext{
${ }^{19}$ Although the actual effective costs are difficult to gauge, the evolution of spread between the deposit and loan rates might have somewhat reflected regime changes in these costs. It declined from 4.3 percent for 1980-82 to 2.3 percent for 1987-96 (see dot-dashed line in Figure 2).

${ }^{20} \mathrm{~A}$ calibration using a production function with decreasing returns to capital did not work well in terms of generating gradual financial deepening.

${ }^{21}$ They find potentially large welfare gain, but the range is quite wide, 0.03 percent to 34 percent.
} 


\section{B. Recursive Formulation}

Because it is difficult to obtain analytic solutions that maximize life time utility (8) for non-participants, we use numerical methods. More specifically, we use dynamic programming, transforming the original maximization problem at the initial date to a recursive maximization problem conditional on two states, assets and participation status in the financial system. ${ }^{22}$ Following the notation of Greenwood and Jovanovic (1990), we define $V\left(k_{t}\right)$ as the value for those who have already joined financial intermediaries today, and $W\left(k_{t}\right)$ as the value for those who have not joined today but have an opportunity to do so tomorrow. Also, we introduce a pseudo $W_{0}\left(k_{t}\right)$ as the value for those who are restricted to never ever joining. These value functions are defined as follows. For participants, ${ }^{23}$

$$
V\left(k_{t}\right)=\max _{s_{t}} u\left(k_{t}-s_{t}\right)+\beta \int V\left(k_{t+1}\right) d F\left(\theta_{t}\right)
$$

subject to the wealth accumulation process (6);

for nonparticipants,

$$
W\left(k_{t}\right)=\max _{s_{t}, \phi_{t}} u\left(k_{t}-s_{t}\right)+\beta \int \max \left\{W\left(k_{t+1}\right), V\left(k_{t+1}-q\right)\right\} d H\left(\eta_{t}\right)
$$

subject to the wealth accumulation process (1); and

for never-ever-joiners

$$
W_{0}\left(k_{t}\right)=\max _{s_{t}, \phi_{t}} u\left(k_{t}-s_{t}\right)+\beta \int W_{0}\left(k_{t+1}\right) d H\left(\eta_{t}\right)
$$

subject to the same wealth accumulation process (1).

We can write an equivalent formulation in which the participation decision is made at the beginning of each period. It is simply defined as

$$
Z\left(k_{t}\right) \equiv \max _{d_{t} \in\{0,1\}}\left\{W\left(k_{t}\right), V\left(k_{t}-q\right)\right\}
$$

where $V\left(k_{t}-q\right)$ represents the value for new participants today.

\section{Solutions of Value Functions and Policies}

For non-participants with value $Z(k)$, the savings $s$ and the portfolio share $\phi$ are functions of wealth $k$, and must be obtained numerically. Since the economy grows perpetually, we cannot apply a standard numerical algorithm, which requires an upper bound and a lower bound of wealth level $k$. Fortunately, the participant's value $V(k)$ and the never-ever-joiner's value $W_{0}(k)$ have closed form

\footnotetext{
${ }^{22}$ With some additional technical assumptions we can establish the equivalence of solutions between these two formulations. See proofs in Townsend and Ueda (2001).

${ }^{23}$ In practice, participation decision $d_{t}$ will be zero for several periods and then jump to one and stay there, that is, no one will ever exit the financial sector in this transitional growth model. See proof in Greenwood and Jovanovic (1990).
} 
solutions together with the associated optimal savings rate and portfolio share, as follows for the log-utility case. ${ }^{24}$ For participants

$$
V(k)=\frac{1}{1-\beta} \ln (1-\beta)+\frac{\beta}{(1-\beta)^{2}} \ln \beta+\frac{\beta}{(1-\beta)^{2}} \int \ln r(\theta) d F(\theta)+\frac{1}{1-\beta} \ln k,
$$

with the optimal savings rate $\mu \equiv s / k=\beta$; and for never-ever-joiners,

$$
\begin{aligned}
W_{0}(k)= & \frac{1}{1-\beta} \ln (1-\beta)+\frac{\beta}{(1-\beta)^{2}} \ln \beta \\
& +\frac{\beta}{(1-\beta)^{2}} \int \ln e^{* *}(\eta) d H(\eta)+\frac{1}{1-\beta} \ln k,
\end{aligned}
$$

with the optimal savings is $\mu^{* *}=\beta$ and $e^{* *}(\eta)=\phi^{* *} \eta+\left(1-\phi^{* *}\right) \delta$, where $\phi^{* *}$ is the solution to the relevant first order condition. We utilize these two boundary value functions $V(k)$ and $W_{0}(k)$ to compute nonparticipant's values $W(k)$ and $Z(k)$ following the numerical algorithm described in Townsend and Ueda (2006).

\section{Setup For Numerical Analysis}

We analyze quantitative properties of the model by looking at numerically constructed expected paths. Although each household's return is not affected by the choice of others, it does depend on each household's wealth. As a consequence, "macroeconomic" variables such as the growth rate of per capita income and the bank participation rate vary with the entire wealth distribution of participants and nonparticipants. Further, the transitional evolution of all these variables should be viewed as one possible sample from the draw of an entire history of aggregate and idiosyncratic shocks.

The Thai economy experienced rapid economic growth and financial deepening prior to the financial crisis of 1997, and we calibrate the model against 20 years of data, from 1976 to $1996 .{ }^{25}$ The basic parameter values are the same as in Townsend and Ueda (2006), based on multiple sources of data. In particular, the initial wealth distribution and the initial number of households having formal sector bank accounts come from nationally representative household survey, the Socio-Economic Survey (SES), ${ }^{26}$ and the per capita real GDP growth rate is from the IMF World Economic Outlook database (originally from the Thai government). ${ }^{27}$ In addition, the return of safe and risky assets are from the

\footnotetext{
${ }^{24}$ We omit time subscript $t$ in the value functions because individuals face the same problem in each period given the current wealth level $k$. For detailed derivation of solutions in this section as well as with a more general CRRA utility, see Townsend and Ueda (2006).

${ }^{25}$ See discussions in concluding remarks on the Asian crisis.

${ }^{26}$ Note that the surveys (SES) were taken in 1976 and then biannually from 1980.

${ }^{27}$ The range of aggregate shocks is consistent with historical variations in the per capita real GDP growth rate. The mean of the aggregate shocks is picked by a calibration exercise under simplified assumptions. Note also that compact supports for distributions of shocks are used in the proof of existence of the optimal path for the perpetually growing economy (Townsend and Ueda, 2001).
} 
Townsend-Thai data. ${ }^{28}$

Under these and other parameter values, Townsend and Ueda (2006) show that the model simulation follows reasonably well the overall trends of growth, financial deepening, and changing inequality in Thailand for the 1976 to 1996 period. The benchmark parameter values are summarized in Table $1 .^{29}$

Table 1. Parameter Values

\begin{tabular}{|c|c|c|c|c|c|c|}
\hline$\sigma$ & $q$ & $\delta$ & $\theta$ & $\epsilon$ & $\beta$ & $1-\hat{\gamma}$ \\
\hline 1 & 5 & 1.054 & {$[\mathbf{1 . 0 4 7}, \mathbf{1 . 1 4 7}]$} & {$[-0.6,0.6]$} & 0.96 & 0 \\
\hline
\end{tabular}

Computed value functions for the benchmark parameter values are shown in Figure 5. The nonparticipant's value $W(k)$ is always between participant's $V(k)$ and never-joiner's $W_{0}(k)$. It approaches $W_{0}(k)$ as $k$ goes to zero and coincides with $V(k-q)$ for large $k$. The critical level of wealth to join the bank is $k^{*}=15$, the minimum capital level such that $Z(k)$ and $V(k-q)$ coincide.

The saving rate of nonparticipants increases with their wealth level up to near the critical level of capital $k^{*}$ that determines the entry decision (Figure 6). ${ }^{30}$ This is due to intertemporal consumption smoothing, preparing for payment of the fixed fee. Also, nonparticipants have an incentive to save more than participants so that they can accumulate wealth faster to start utilizing the financial service. The higher savings rate of nonparticipants implies that the economic growth rate may become lower with more financial participation.

The portfolio share of risky assets varies in Figure 6 as expected around the optimal level $\phi^{* *}$ under $W_{0}(k)$, the value function of those who are never ever allowed to enter the bank. It increases first and then decreases. It is, however, almost always larger than $\phi^{* *}$ for $k<k^{*}$. That is, nonparticipants put their wealth in the risky asset as a natural lottery to convexify their life-time utility (value function)—see Proposition 1 in Townsend and Ueda (2006). In other words, nonparticipants invest more in risky assets than never-joiners by hoping that they can enter financial system earlier. Those chances are low for very poor people, and the figures show that both the saving rate and portfolio share approach those of those who are never ever allowed to join the bank as wealth goes to zero. Note that the aggregate return on savings is higher when more households join the financial system as banks always select more profitable projects between safe and risky ones. However, wealth growth also depends on the savings rate, which may be lower with more participants.

\footnotetext{
${ }^{28}$ The safe return is set at the median net return from capital investment in agriculture. The range of the uniform distribution of idiosyncratic shocks comes from the difference between top 1 and 99 percent of income-to-capital ratio for those nonagricultural business with no access to the formal financial system. Note that, with a small number of survey years, it is difficult to distinguish idiosyncratic shocks from common shocks. Detailed information on Townsend-Thai data is available in Townsend and others (1997), and also at the web page: http://www.src.uchicago.edu/users/robt.

${ }^{29}$ These benchmark parameter values are very close to the estimates by Jeong and Townsend (2006).

${ }^{30}$ It then decreases slightly for the wealth level larger than the critical value $k^{*}$. This is the region showing off-the-equilibrium path, in which households should have participated in the financial system already. See Townsend and Ueda (2006) for a more detailed discussion.
} 
Using these numerically obtained savings and portfolio share functions, we generate the evolution of wealth distribution and participation status starting from the 1976 wealth distribution of SES. Then, we use the numerically obtained wealth distribution each year from 1976 to 1996 to draw aggregate growth and financial participation rate. Apart from the benchmark parameter values, the path of cost parameters $\gamma$ and $q$ and the path of aggregate shocks $\theta_{t}$ are specified in the next section. Note that the initial fixed cost $q$ is used as a scale parameter, on the assumption that future policy changes come as a surprise (that is, the agents assume that the initial fixed and marginal costs are constant forever.) Given other parameter values, the initial fixed cost $q$ determines the critical value of wealth under which people in the model join the financial system. As the participation rate is 6 percent in 1976, we compare 94th percentile of the initial wealth distribution and the critical capital level $k^{*}$ to pin down pin down the "exchange rate" between the model unit to the Thai baht. In the experiment we change the fixed cost in later years, this exchange rate is kept constant.

\section{Vi. Calibration}

Our aim is not to show how well the model explains the movements of GDP growth, but to determine how large are the effects of financial liberalization on growth and welfare after allowing for aggregate shocks that make the model-generated data trace the actual GDP growth rates. To disentangle the importance of financial sector policy changes from these common aggregate shocks, we display simulated movements of the growth rate and financial deepening under various specifications. Specifically, we compare and contrast three experiments: (i) aggregate shocks at their mean with a constant zero variable cost, (ii) actual GDP growth rates as the aggregate shock but again with a constant zero variable cost, (iii) calibrated growth rates as the aggregate shock with the variable cost movements calibrated from the policy changes. Essentially, we choose the aggregate shocks to match the observed GDP growth rate, and then focus on how well the model tracks actual financial deepening under these shocks. ${ }^{31}$

Figure 7 shows the first experiment with aggregate shocks constant at their mean expected value each period and a constant zero variable cost. The evolution of growth and financial sector participation are almost identical with the movements of the average of 1000 Monte Carlo simulations reported in Townsend and Ueda (2006). The evolution is too smooth to predict flattening of the financial sector participation in 1980-82 and the upturn in financial sector participation in 1987-89 and fluctuations and upturn in the growth rate in 1987.

Figure 8 shows the second specification with the actual growth rate fed in as the aggregate shock and with the same constant cost. ${ }^{32}$ Apparently, the growth rate is well mimicked though still a bit short

\footnotetext{
${ }^{31}$ Though regression analysis may be an unwise strategy to identify the effects of financial liberalization, if conducted, we would at least control for other factors affecting GDP growth rates: for example, trade openness, capital flows, exchange rates, year dummies for political turmoils, and so on. Here, in our simple model, aggregate shocks can stem from any of those potential factors. To identify the effects from financial liberalization, we need to control for those factors by using the specific shocks that makes the model-generated data match well with the actual GDP growth rate data.

32 Unlike stationary series, the model generates highly non-stationary and non-ergodic time series as transitions to a long-run steady state. Hence, the Solow residuals cannot be used as TFP shocks as inputs to the simulation. Rather, we use the actual GDP growth rate as an input. This needs to be scaled up when used as an input in the model as the aggregate shock, because savings and portfolio choice are additional factors determining endogenous growth. Ultimately, we calibrate these shocks using the actual GDP growth rates as initial shocks, only.
} 
on the upturn, but there is little variation in the participation rate from its average trend. Aggregate shocks alone fail to explain the movements in financial deepening. Something more is needed to explain the path of financial deepening, with its flattening and subsequent upturn, even though shocks can be selected to mimic observed GDP growth. ${ }^{33}$

We now experiment with changes in variable costs. From the historical evidence pictured in Figure 4, we guess there were three regime changes. Average credits to the government sector, which corresponds to $\alpha$ in the model, are 10.8 percent of total credit before 1980, 30.2 percent for the period between 1980 and 1986, 8.3 percent between 1987 and 1989, and -0.2 percent after 1990. ${ }^{34}$ We fix the public sector inefficiency level $z$ to be 0.95 ; that is, the investment return is always 5 percent less if the government conducts business. Assuming intrinsic costs are zero, the effective variable costs $(1-\hat{\gamma})$ for these four periods are then estimated at $0.5,1.5,0.4$, and 0 percent, respectively. ${ }^{35}$ The dashed line in the bottom box of Figure 9 shows government's share in new bank lending with $z=0.05$, and the solid line is our characterization of the evolution of that policy. Note that though we choose government inefficiency $z$, we do not freely choose the timing and overall effects of government share in new bank lending. Also note that we assume here that both size $\alpha$ and inefficiency $z$ of government are structural parameters and that households take a specific policy regime as given. Hence the change in regime comes as a surprise. ${ }^{36}$

With this historical evolution of the financial sector policy, simulated financial deepening traces the actual data well (see Figure 9). Though initial aggregate shocks are again based on the actual GDP growth rates, subsequently forecast errors are then added, and the result, after this one-step iteration, matches actual GDP growth well. Indeed, we could further iterate until we mimic the actual data almost perfectly. But we report the results based on this one-step iteration alone, since there is a remarkable resemblance between the simulated and actual data in Figure 9. ${ }^{37}$ Again, the focus should be on the success in matching financial deepening, which stagnates in the repression and surges in the liberalization.

\footnotetext{
${ }^{33}$ This result is in line with Townsend and Ueda (2006). They have a different objective; that is, they look at the joint explanatory power in terms of growth, inequality, and financial deepening. Their best fit simulation is taken out of 1000 simulations with varying aggregate shocks, based on a covariance-normalized distance from actual growth, financial participation, and inequality data, simultaneously. The best fit path succeeded somewhat in replicating the GDP growth rate, but did not deliver the dynamic changes from mid-1980s, especially in financial participation and inequality.

${ }^{34}$ The after-1989 number is the 1990-1996 average. The before-1980 number is the 1977-1979 average, as there was a change in statistical definition in 1976.

${ }^{35}$ Also, the overall 1.5 percent decline in 1987-1989 is consistent with the actual decline of the spread between the deposit and loan rates from early to late 1980's, shown in Figure 2.

${ }^{36}$ In a more general case, size and inefficiency of government can be formulated as a stochastic process, possibly with Markov properties. In this case, households anticipate a regime change with some positive probability. However, a simulation with only varying aggregate shocks would still produce too smooth financial deepening, so that our main argument remains unchanged: aggregate shocks and unanticipated financial sector policy changes are both necessary to trace the actual Thai data. By an argument similar to previous footnote, 32, it would be hard to identify policy shocks in a more general model.

${ }^{37}$ The overall picture is quite similar if we use only the actual GDP growth rates without the one-step-iteration. However, we prefer to use a better measure of aggregate shocks, to mimic the actual GDP growth, so that we can evaluate the gains in growth and welfare more accurately in the next section. Note that identifying a specific aggregate shocks are important to generate the actual growth pattern of Thailand, as a generated growth pattern is too smooth but with a few bumps and dips in a simulation with changing variable costs but with aggregate shocks constant at their mean expected value each period.
} 
Similarly, the calibration study can be carried out changing the entry costs, keeping the variable cost constant (at zero). Unlike the variable cost case, we do not have specific information on entry cost movements and we rely on try-and-error estimates but keep the timing as same as in the variable cost case. Figure 10 displays the final results, analogous to Figure 9. To trace the actual data, the entry cost rises 40 percent (from 5 to 7) in 1982, declines to the original level in 1987, and then declines an additional 10 percent (from 5 to 4.5) in 1989. Again, we could iterate further on both TFP shocks and financial sector policy changes to deliver an even closer fit, but the match is already quite good.

Finally, similar figures can be drawn for different parameter settings; for example, a case with a lower safe return $(\delta=1.047)$ in Figure 11 and with a higher risk aversion $(\sigma=1.5)$ in Figure $13 .{ }^{38}$ We discuss these robustness checks in detail later.

\section{WeLFARE GAINS}

As shown in the calibration exercises in the previous section, de facto financial liberalization occurred in 1987-89, associated with a reduction of the variable cost from 1.5 to 0 percent or reduction of the entry cost from 7 to 4.5. We now ask a new question: What would be the effects on growth and welfare of this financial liberalization compared to what would have happened if the repression had continued?

For simplicity, and contrary to Figures 9 and 10, we compare a once-and-for-all liberalization in 1987 versus continued repression. Specifically, we simulate the economy as in the previous section using the same iterated shocks and policy path, but in 1987 we reduce the variable cost from 1.5 to 0 and calculate the annualized growth rate thereafter, from 1987 to 1996 . Table 2 shows that the gain in the annualized growth rate for the $1987-1996$ period is 0.59 percent; that is, 6.87 percent with the reduction and 6.28 without the reduction, using the iterated sequence of aggregate shocks, the same one as for Figure 9. The gain is -0.17 percent, from 6.99 to 7.16 percent, with the reduction of entry cost, using the sequence of shocks that generated Figure 10. Note however that in both these experiments, we are using shocks calibrated to actual growth experience with the policy change, yet we are asking what would have happened without a policy change, a counterfactual. Thus, as a robustness check, we also use the expected shocks from 1987 on. The growth difference is estimated at 0.96 percent with the variable cost reduction and -0.26 percent with the entry cost reduction.

The point is that the reductions in costs do not induce much growth in most of our simulations. There are two reasons: (i) an increase in the endogenous entry cost payments (and reduction in productive inputs) right after the financial liberalization as more households enter; and (ii) a drop in the aggregate savings as participants have a lower savings rate than nonparticipants. ${ }^{39}$

While movements in public debt financed by banks suggest that the de facto financial liberalization in Thailand in this period is more likely to be associated with a reduction in the variable costs, episodes in other countries and other periods may be associated with a reduction in the entry cost. As

\footnotetext{
${ }^{38}$ With a higher risk aversion, we need to iterate twice to find a sequence of aggregate shocks to mimic the actual GDP growth rate.

${ }^{39}$ Both effects change over time and thus the growth rate depends on which years we choose as starting and terminal years.
} 
such, our results are consistent with the literature, which does not find decisive favorable evidence for enhanced growth associated with financial liberalization.

Still, a low growth effect does not preclude a high welfare gain. Households choose to have lower growth rates as a consequence of their optimizing behavior. For participants, we have a closed form solution of the value function (14). This makes clear the gains from a lower marginal cost, namely from the increase in the return $r(\theta)$. Of course, there is no gain to participants from changes in the entry cost, because they are already in the financial system. For nonparticipants, there is no closed-form solution, so the welfare gains for them must be computed numerically. Specifically, we compare the value function $Z(k)$ of nonparticipants with and without liberalization, the 1.5 percent variable cost reduction. The value function with liberalization is reported as the solid line and one without as the dashed line, both in the upper left quadrant of Figure 15. Nonparticipants' values $Z(k)$ are drawn for the wealth level below the critical value of wealth, around 25 associated with 1.5 percent variable cost. Above 25, the participants' values $V(k)$ are plotted. ${ }^{40}$ The difference in the lifetime utility value from the reduction in the variable cost is reported in the lower left quadrant of Figure 15 . Note that the utility compensation naturally depends on wealth. Low wealth households are so far from the date of entry that the future utility gains are of little consequence.

Nonparticipants' utility gains increase with wealth and seemingly converge to those of participants.

We report the welfare gain in the monetary units as the corresponding wealth compensation, ${ }^{41}$ the amount of transfer one would have to give to an agent with wealth $k$ under the repression in order to get her life time utility up to the value she would have under the liberalization. ${ }^{42}$ Specifically, let $\hat{Z}$ denote the value function for nonparticipants after the reduction of variable cost (liberalization) and $Z$ the previous value function (repression). The wealth compensation $\tau$ is defined as follows:

$$
\hat{Z}(k)=Z(k+\tau) \text {. }
$$

The upper right quadrant of Figure 15 shows this wealth compensation, ${ }^{43}$ and the lower right quadrant shows this wealth compensation relative to the wealth levels, that is, compensation in

\footnotetext{
${ }^{40}$ Note that the critical value of wealth is about 15 after the variable cost is reduced to zero. Households with wealth between 15 and 20 would have participated the financial system and face the participant's value function $V(k)$ if the cost had been always zero. However, right after the cost is reduced, the households with wealth between 15 and 25 immediately join the financial system and face the value function of new participants $V(k-q)$, which comprises $Z(k)$.

${ }^{41}$ The welfare gains from risk sharing vary with the choice of distribution of idiosyncratic shocks as well as the utility function. We have used the log utility and assumed the uniform distribution of idiosyncratic shocks with the range based on the Townsend-Thai data. A log normal, rather than uniform distribution, would possibly give us a lower welfare gains. But on the other hand, our benchmark assumption of at most \pm 60 percent gross return is a conservative estimate of income variation, as there would be no households anywhere near bankruptcy or a doubling wealth in one year, as these are in the data. The welfare gains in terms of permanent consumption may be underestimated with the assumption of 100 percent depreciation of capital, because stock of savings relative to consumption is larger for the economy with low depreciation rate of capital and inefficient investments lowers the value of capital.

${ }^{42}$ This concept corresponds to transfers used in Hicks compensation principle. A similar concept is appeared in Townsend and Ueda (2001) as well as in Epaulard and Pommeret (2003). A similar concept, Kaldor compensation, is the amount of wealth that a consumer would happy to give up after liberalization was taken to get the utility down to its previous value. We use Hicks compensation, as it is computationally easier.

${ }^{43}$ To smooth out the computational errors, a fitted values (solid line) is drawn based on a cubic regression for the nonparticipant's case.
} 
percentage terms. Among all nonparticipants, those who are just below the threshold of participating in the financial system, under the 1.5 percent cost, benefit the most from the financial liberalization. ${ }^{44}$ That is, the gain is increasing with wealth and reaches 35.2 percent just before entry. However, participants' gain from the reduction of variable cost is 43.7 percent, based on the closed form solution (see Appendix), so there is a discreet jump in the wealth compensation between the nonparticipants and participants - due to the different curvatures of the value functions.

Welfare gains from the reduction in the entry cost can be calculated similarly and are shown in Figure 16. The graphs share many of the qualitative features of the variable cost version but display lower welfare gains at all wealth levels. ${ }^{45}$ Recall that, unlike a reduction in the variable cost, the reduction in the entry cost does not benefit the participants. So, nonparticipants' gains do not converge to participants' gains (zero). Rather, the benefits are concentrated among the middle wealth households who are likely to join the financial sector in the near future. ${ }^{46}$ Also, note that between two critical values of capital, 14 and 21, welfare gains appear to decrease, from the peak of around 13 percent. Once households start using financial system, their gain from entry cost reduction is zero. Hence, the benefits of a lower entry fee are restricted to wasting fewer resources and starting earlier. The former effect, after discounting for expected periods left before joining, is always larger for richer nonparticipants. The latter effect depends on the change of the expected entry date and it is small for both very poor households, who would join in a distant future in any regime, and for rich nonparticipants, who were close to the critical capital level.

To begin to compare with the literature, we compute the "aggregate" welfare gain from the 1987-89 financial liberalization. To get one number, we need to integrate the wealth-dependent welfare gains using the wealth distribution at 1987 . The latter is obtained by simulating the economy under the benchmark parameter values and the iterated aggregate shocks up to 1987. Note that the aggregate compensation varies with histories of costs and shocks, which determine the distribution of participation status at 1987. Table 3 reports the result: the aggregate compensation is about 27

\footnotetext{
${ }^{44}$ In Figure 15, the critical values of capital such that an individual joins the financial system is around 15 and 25 for zero and 1.5 percent variable costs, respectively.

${ }^{45}$ In Figure 16, the critical values of capital such that people join the financial system are around 14 and 21 for 4.5 and 7 entry costs, respectively. At the low end, there must be a computational/numerical error-wealth compensation is not really zero.

${ }^{46}$ In one alternative interpretation, costs are not intrinsic, but all costs are paid to bankers as their income. In another, alternative interpretation, there are intrinsic costs but the difference between the true costs and the current costs are the income of bankers. In either case, an increase (or decrease) of costs might appear to be just transfers with no net gain. This is not the case, assuming the bankers have the same value function as participants. In the case of a variable cost reduction, the bankers' welfare gain would be just a change in their wealth under the same value function, but nonparticipant household would experience not only a change in their wealth, but also a upward shift of their value function $Z(k)$. Hence, aggregate gains should be positive. Similarly, in the case of entry cost reduction, positive welfare gains are likely to emerge. For example, consider the case in which the entry cost is reduced from 7 to 4.5 . Households would obviously appreciate this change, though not as much as 2.5 , as they do not need to pay the fee right now under the old, high costs. At the same time, the bankers lose transfer of 2.5 from each new participant, but there will be many more new participants today under the lower costs. As a result, the current period revenue is probably bigger even with the reduced entry costs. Also, all the future entrants would enter earlier and thus future revenues of bankers would realize faster, contributing to the net present value of income stream of bankers. In any case, as Greenwood and Jovanovic (1990) show, it is Pareto optimal and a competitive equilibrium result to set the price of financial service at the intrinsic costs.
} 
percent of the aggregate wealth ${ }^{47}$ for the case of reduction in the variable cost. It is about 14 percent for nonparticipants and 44 percent for participants. Their share of wealth is about the same, so the overall number is close to a simple average. As for the the entry cost reduction, the welfare gain is about 2 percent. As the entry cost reduction affects only nonparticipants, the participants' gain is zero. Nonparticipants, who have approximately one half of the wealth in 1987, have welfare gains of about 4 percent. ${ }^{48}$

\section{Discussion}

\section{A. Sensitivity Analysis}

To check on sensitivity, we replicate our results using a lower safe return, $\delta=1.047$ (see Figure 11 for the variable cost reduction case and Figure 12 for the entry cost reduction case). This corresponds to the lowerbound of the risky return, so the all the savings of participants go to the risky asset, regardless of $\theta$. Thus, there is no informational gains and all the welfare gains from intermediation are from risk insurance. Apparently, the direct benefits of joining the financial system become lower, but more complex dynamics are brought about by the process of financial deepening. Indeed, the growth effect and welfare gains (Tables 4 and 5) are the virtually identical to the benchmark case. ${ }^{49}$ Actually, both are slightly higher. This is because the lower safe return makes nonparticipants allocate their wealth more to risky projects, resulting in higher idiosyncratic volatility in income. As such, they would like to join the financial system earlier. Hence, at 1987, more people have already participated, making overall growth and welfare gains higher for the variable cost reduction case, as participants receive highest welfare gains. ${ }^{50}$ As for the entry cost reduction case, the welfare gains for nonparticipants themselves are higher, although there are no gains for participants and the participation rate at 1987 is higher.

We also replicate the results using a higher relative risk aversion $\sigma=1.5$ (see Figure 13 for the variable cost reduction case and Figure 14 for the entry cost reduction case). ${ }^{51}$ With higher risk aversion, participants save less, ${ }^{52}$ and thus a change in net-of-cost return has a smaller effect on the

\footnotetext{
${ }^{47}$ We compute total compensations for all households and then divided by aggregate wealth. This exercise simulates a policy experiment in which a central planner determines the total amount of transfers. Note that we are not calculating a simple average or a wealth-weighted average of the wealth transfer.

${ }^{48}$ This 4 percent gain is about a quarter of the variable cost case, 14 percent. This lower gain stems partly from the shape of wealth-dependent welfare gains, as the peak gain, 13 percent, is more than a quarter of the variable cost case, 44 percent. Also, history matters, as both the population proportion and income shares of nonparticipants at 1987 are lower in the entry cost reduction experiment.

${ }^{49}$ Note that in both variable cost reduction and entry cost reduction cases, the iterated shocks necessary to mimic the GDP growth data are basically identical to those in the benchmark case, as reported in the last rows of Tables 4 and 5 .

${ }^{50}$ Participants' welfare gains turned out to be the same as in the benchmark case.

${ }^{51}$ The iterated shocks necessary to mimic the GDP growth data are much higher than those in the benchmark case, as reported in the last rows of Tables 4 and 5. This implies that the set of parameter values is less likely generate the actual Thai data.

${ }^{52}$ With a $\log$ utility, the savings rate is constant at $\beta$ regardless of returns. With a CRRA utility, the savings rate depends on the relative risk aversion parameter and the mean and variance of returns, $\mu^{*}=\left\{\beta E\left[r(\theta)^{1-\sigma}\right]\right\}^{1 / \sigma}$ (see Townsend and Ueda (2006) for the derivation).
} 
lifetime utility. As such, the welfare gains for participants becomes lower, and so do those for nonparticipants, who expect to become participants in the future (see Table 4). Growth rates can be higher (under the iterated shocks) or lower (under the mean shocks) than the benchmark case. The result is similar in the case with entry cost reduction (see Table 5).

\section{B. Comparison to Business Cycle Literature}

Most of the literature expresses welfare gains in terms of changes in the permanent consumption, not a one-time wealth transfer. Here, as all the important movements happen in transition, it is not fruitful to identify the gain in terms of steady state permanent consumption. In addition, with the entry cost, there is a wealth effect on savings, and thus we cannot pin down exactly the relationship between changes in levels and growth rates.

Still, as an approximate number and for comparison, we do now consider the growth path given by CRRA utility and a simple $A k$ type linear technology. Steady state growth is always linear, and both capital and consumption grow at the same rate. This would be case for the participants and never-ever joiners, each in isolation. ${ }^{53}$ Thus, a one-time change in levels does not affect the growth rate. Specifically, a one-time 27 percent increase in wealth implies that, in any subsequent period, wealth and consumption levels are always 27 percent higher than the levels without such an income transfer.

Our exercise is different from the literature on welfare gains from risk sharing in three dimensions. First, existing studies compare current volatility to no volatility (domestic business cycle) or to perfect risk sharing among countries (international risk sharing). Apparently, any endogenous choice of risk sharing activity is not typically taken into account. Second, in our model, not only risk sharing but also an informational advantage increases the welfare gain. Finally, our study focuses on domestic, individual-level volatility, which is quite high, rather than the volatility of macro variables, in which individual shocks are averaged out by construction.

Figure 17 shows that the welfare gains moving from autarky, $W_{0}(k)$, to the perfect participation, $V(k)$, with no cost. This exercise is similar to what the existing literature does, namely, exogenously turning off and on the advantage of financial system. The utility gain is constant in the model unit. Specifically, by definitions of $V(k)$ and $W_{0}(k)$ in (14) and (15), the difference is

$$
\frac{\beta}{(1-\beta)^{2}}\left(\int \ln r(\theta) d F(\theta)-\int \ln e^{* *}(\eta) d H(\eta)\right)=19.3
$$

This gain from a regime change combines the efficiency gain in expected return (in logarithm) and the gain in risk sharing (the reduction in variation of outputs). The utility gain if the risky assets return its mean values deterministically would be

$$
\frac{\beta}{(1-\beta)^{2}} \ln \int r(\theta) d F(\theta)-\ln \int e^{* *}(\eta) d H(\eta)=15.0 .
$$

\footnotetext{
${ }^{53}$ In particular, with the log utility, the savings rate is always equal to the discount rate $\beta$ and growth rates of wealth and consumption are $\beta A$. A similar linear growth rate can be obtained for CRRA utility functions with any values of $\sigma$.
} 
This corresponds to the efficiency gain. It explains about 3/4 of the total gain and the remaining 1/4 comes from gains in risk sharing in the log utility case. ${ }^{54}$

In terms of wealth compensation, the total gain is constant ${ }^{55}$ at 116 percent in the log utility case, much higher than our earlier numbers. ${ }^{56}$ Hence, around 30 percent (1/4 of 116) of wealth is the compensation for the risk sharing. This is quite large compared to the literature, but close to the upper-end of the welfare gain reported in Epaulard and Pommeret (2003) — and again we have larger volatility at the individual level. Note also that a larger gains come from the growth effects, consistent with Alvarez and Jerman (2004), who show that large welfare gains, more than 1000 percent, are possible by eliminating longer-term trend movements in GDP growth rates.

Again, the advantage of this on-off experiment is that it is directly comparable to the literature. We emphasis, however, that the on-off experiment does not correspond to the reality of financial liberalizations. We prefer our earlier estimates of welfare gains. Moreover, the decomposition of gains from risk sharing and from an increase in efficient investment allocation depends on parameter values. In some specification, the gains from risk sharing could explain almost all the welfare gains. Indeed, as we reported in the previous section, the welfare gains stem from risk sharing alone in the case of a lower safe return. This result is clearly different from on-off experiments. Also, our sensitivity analysis in the previous section shows that effects of higher risk aversion depend on the characteristics of a policy change, something which we could not see from the on-off experiment.

\section{CONCLUding Remarks}

This paper contributes to a lively debate on financial liberalization. We report welfare gains based on an endogenous financial deepening model calibrated to an actual financial liberalization episode. To the best of our knowledge, there is nothing like this in the literature. Financial repression and liberalization are represented as changes in variable and entry costs for the financial services. Those changes in costs affect both financial deepening and economic growth. Based on the historical events, we report a de facto evolution of financial sector policy in Thailand from 1976 to 1996, in particular, a repression and then a significant financial liberalization in 1987-1989. We evaluated this specific financial liberalization episode in terms of growth and welfare gains, allowing for potential factors which might affect growth by using a sequence of aggregate shocks that makes the model trace the actual path of GDP growth.

We find a sizable welfare gains, although the model predicts, consistent with the literature, ambiguous effects on growth. Specifically, we find welfare gains as high as 1-28 percent of permanent consumption, while the effects on subsequent economic growth range from -0.2 to 0.7 percent. Note that those numbers would change depending on the income level and the degree of

\footnotetext{
${ }^{54}$ As more risk averse households allocate larger portion of wealth into the safe projects, the gains from improvements in the mean return may become larger with a higher risk aversion. For example, when $\sigma=1.5$, the efficiency gain explains about 87 percent of the total gain.

${ }^{55}$ There is some numerical error near zero.

${ }^{56}$ With higher risk aversion, $\sigma=1.5$, the welfare compensation is about 92 percent of the wealth. It is smaller than the $\log$ utility case, partly because the savings rate (and so wealth growth) becomes lower with better risk insurance and because the optimal portfolio under autarky is not so volatile with a higher weight in safe projects.
} 
financial deepening of a country, and more precisely on the underlying historical evolution of wealth. Moreover, welfare gains are not distributed equally among households. For nonparticipants, the gains must have been larger for those who have relatively large wealth and were about to enter the financial system in the near future. Participants received benefits only from the reduction of the variable cost, not the entry fee.

Since an imperfect financial sector prevails both before and after the liberalization in the model with endogenous financial deepening, we are able to report more realistic gains in welfare and growth. Moreover, we show that some insights do not carry over from on-off experiments. Specifically, we find the risk sharing role in the welfare gains can be much larger than an on-off experiment suggests.

Of course, we regard this paper as a first step only. We are pleased and surprised by how well we do in tracking the actual data and in dating de facto repressions and liberalizations. There is a close match with historical evidence. However, in focusing on financial deepening and growth, we recognize that we have neglected other factors through which finance may affect growth and the welfare calculations; for example, credit constraints to start new business and liquidity needs to continue business. More narrowly, although the welfare gains from risk sharing on reduced individual volatility are sizable, simplistic assumption have been made: a specific distribution for the aggregate and idiosyncratic shocks, perfect risk sharing for those in the financial system, and no risk sharing for those in financial autarky. Further, even if the model were literally true, we have nevertheless abstracted from the expectations of policy changes. The interventions we studied are modeled as surprise changes in costs, not anticipated in advance. It is true that rules and regulations do not change every day, but as we model it here, on the other hand, regime change is not likely to come as a complete surprise.

There is also a caveat on the specific years we selected. The Asian Crisis started in Thailand 1997, one year after our sample period. One of the triggers was a large percentage of nonperforming loans. Presumably this is associated with inefficient lending, in particular to real estate, in years prior to 1997. Hence, our assumption of an efficient allocation of capital by private banks might not be true in mid 1990's, preceding the crisis. If so, our estimates of welfare gains from liberalizations in the middle of 1980's are overstated. But we would like to leave this debate for future efforts.

In summary, a more realistic model would alter the welfare impacts but would not undercut our general point that an evaluation of financial liberalization needs a model-based study and that policy changes are layered on top of endogenous financial deepening. 


\section{REFERENCES}

Abiad, Abdul, Nienke Oomes, and Kenichi Ueda, 2004, "The Quality Effect: Does Financial Liberalization Improve the Allocation of Capital?," IMF Working Paper, No. 04/112.

Acemoglu, Daron, and Fabrizio Zilibotti, 1997, "Was Prometheus Unbound by Chance? Risk, Diversification, and Growth," Journal of Political Economy, Vol. 105, No. 4 (August), pp. 709-751.

Acharya, Viral V., Jean Imbs, and Jason Sturgess, 2006, “The Efficiency of Capital Allocation: Do Bank Regulations Matter?” Unpublished Manuscript, London Business School.

Alem, Mauro, and Robert M. Townsend, 2007, "An Evaluation of Safety Nets and Financial Institutions in Crisis and Growth.” Unpublished Manuscript, University of Chicago.

Alvarez, Fernando, and Urban J. Jermann, 2004, "Using Asset Prices to Measure the Cost of Business Cycles,” Journal of Political Economy, Vol. 112, No. 6, pp. 1223-1256.

Bandiera, Oriana, Gerard Caprio, Patrick Hanohan, and Fabio Schiantarelli, 2000, "Does Financial Reform Raise or Reduce Saving?," Review of Economics and Statistics, Vol. 82, No. 2 (May), pp. 239-263.

Beck, Thorsten, Ross Levine, and Norman Loayza, 2000, "Finance and the Sources of Growth," Journal of Financial Economics, Vol. 58 (October/November), pp. 261-300.

Bekaert, Geert, Campbell Harvey, and Christian Lundblad, 2005, "Does Financial Liberalization Spur Growth?," Journal of Financial Economics, Vol. 77, pp. 3-55.

Berglof, Erik, and Stijn Classens, 2003, "Enforcement and Good Corporate Governance in Developing Countries and Transition Economies," The World Bank Research Observer, Vol. 21, No. 1 (Spring), pp. 121-150.

Broner, Fernando A., and Jaume Ventura, 2005, “Globalization and Risk Sharing,” (October). Preliminary Draft.

Devereux, Michael B., and Gregor W. Smith, 1994, "International Risk Sharing and Economic Growth,” International Economic Reiview, Vol. 35 (August), pp. 535-550.

Diamond, Douglas W., 1984, "Financial Intermediation and Delegated Monitoring," Review of Economic Studies, Vol. 51 (July), pp. 393-414.

Epaulard, Anne, and Aude Pommeret, 2003, "Recursive Utility, Endogenous Growth, and the Welfare Cost of Volatility," Review of Economic Dynamics, Vol. 6, pp. 672-684.

Giné, Xavier, and Robert M. Townsend, 1994, "Evaluation of Financial Liberalization: A General Equilibrium Model with Constrained Occupation Choice," Journal of Development Economics, Vol. 74, pp. 269-304.

Greenwood, Jeremy, and Boyan Jovanovic, 1990, "Financial Development, Growth, and the Distribution of Income," Journal of Political Economy, Vol. 98, pp. 1076-1107. 
and Bruce D. Smith, 1997, "Financial Markets in Development, and the Development of Financial Markets," Journal of Economic Dynamics and Control, Vol. 21 (October), pp. 145-181.

Hellman, Thomas, Kevin Murdock, and Joseph Stiglitz, "Financial Restraint: Toward a New Paradigm," 1996, in Masahiko Aoki, Hyung-Ki Kim, and Masahiro Okuno-Fujiwara, eds., The Role of Government in East Asian Economic Development, (Oxford: Clarendon Press), chapter 6.

Hoshi, Takeo, and Anil K. Kashyap, “The Japanese Banking Crisis: Where Did It Come from and How Will It End?," 2000, in Ben Bernanke, and Julio Rotemberg, eds., NBER Macroeconomics Annual 1999, (Cambridge: MIT Press), chapter 3, pp. 129-201.

Jayaratne, Jith, and Philip E. Strahan, 1996, "The Finance-Growth Nexus: Evidence from Bank Branch Deregulation," Quarterly Journal of Economics, Vol. 111, No. 3, pp. 639-670.

Jeong, Hyeok, and Robert M. Townsend, 2006, "Growth and Inequality: Model Evaluation Based on an Estimation-Calibration Strategy," Macroeconomic Dynamics. forthcoming.

Kaminsky, Graciela L., and Sergio L. Schmukler, 2003, "Short-Run Pain, Long-Run Gain: The Effects of Financial Liberalization," IMF Working Paper, No. 03/34.

King, Robert G., and Ross Levine, 1993, "Finance and Growth: Schumpeter Might be Right," Quarterly Journal of Economics, Vol. 108, No. 3 (August), pp. 717-737.

Levine, Ross, Norman Loayza, and Thorsten Beck, 2000, "Financial Intermediation and Growth: Causality and Causes," Journal of Monetary Economics, Vol. 46, No. 1 (August), pp. 31-77.

Lucas Jr., Robert E., 1987, Models of Business Cycles (Oxford: Basil Blackwell).

McKinnon, Ronald I., 1973, Money and Capital in Economic Development (Washington: Brookings Institution).

Obstfeld, Maurice, 1994, "Risk-Taking, Global Diversification, and Growth," American Economic Review, Vol. 84, No. 5, pp. 1310-1329.

"International Capital Mobility in the 1990s," 1995, in Peter B. Kenen, ed., Understanding Interdependence, (Princeton: Princeton University Press), pp. 201-261.

Prasad, Eswar S., Kenneth Rogoff, Sahng-Jin Wei, and M. Ayhan Kose, 2003, Effects of Financial Globalization on Developing Countries (Washington: International Monetary Fund). IMF Occasional Paper 220.

Rajan, Raghuram G., and Luigi Zingales, 1998, "Financial Dependence and Growth," American Economic Review, Vol. 88, No. 3 (June), pp. 559-86.

Ranciere, Romain, Aaron Tornell, and Frank Westermann, 2006, "Decomposing the Effects of Financial Liberalization: Crises vs. Growth," Journal of Banking and Finance, Vol. 30, pp. 3331-3348.

Robinson, David, Yangho Byeon, Ranjit Teja, and Wanda Tseng, 1991, Thailand: Adjusting to Sucess, Current Policy Issues (Washington: International Monetary Fund). IMF Occasional Paper 85. 
Shaw, Edward S., 1973, Financial Deepening in Economic Development (New York: Oxford University Press).

Townsend, Robert M., 1978, “Intermediation with Costly Bilateral Exchange," Review of Economic Studies, Vol. 45 (October), pp. 417-425. , 1983, “Theories of Intermediated Structures," Carnegie-Rochester Conference Series on Public Policy, Vol. 18, pp. 221-272.

Anna Paulson, Sombat Sakuntasathien, Tae Jeong Lee, and Mike Binford, 1997, "Questionnaire design and data collection for NICHD grant Risk, Insurance and the Family, and NSF grants." Unpublished Manuscript, The University of Chicago. and Kenichi Ueda, 2001, “Transitional Growth with Increasing Inequality and Financial Deepening," IMF Working Paper, No. 01/108. , and _ 2006, "Financial Deepening, Inequality, and Growth: A Model-Based Quantitative Evaluation," Review of Economic Studies, Vol. 73, No. 1 (January), pp. 251-293. , and Jacob Yaron, 2001, “The Credit Risk-Contingency System of an Asian Development Bank," Economic Perspectives, Vol. Q3, pp. 31-48.

Ueda, Kenichi, 2006, "Banks as Coordinators of Economic Growth," IMF Working Paper, No. $06 / 264$.

Van Wincoop, Eric, 1999, "How Big are Potential Welfare Gains from International Risk Sharing?," Journal of International Economics, Vol. 47, No. 1, pp. 109-135. 
Figure 1. Financial Liberalization and Gini of Tobin's Q

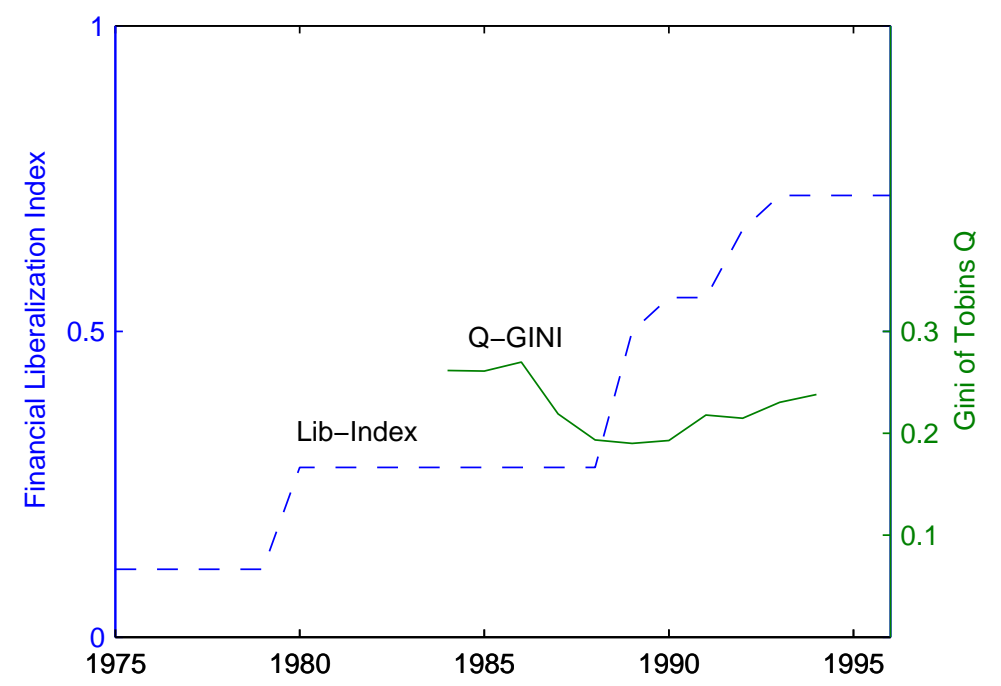

Figure 2. Inflation, Deposit Rate, and Spread

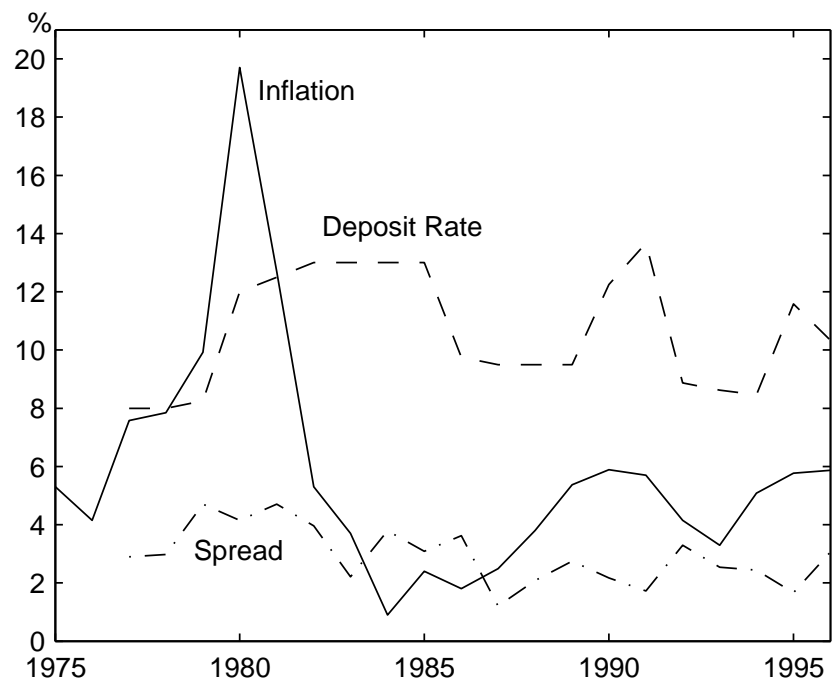


Figure 3. Real Growth of Deposits

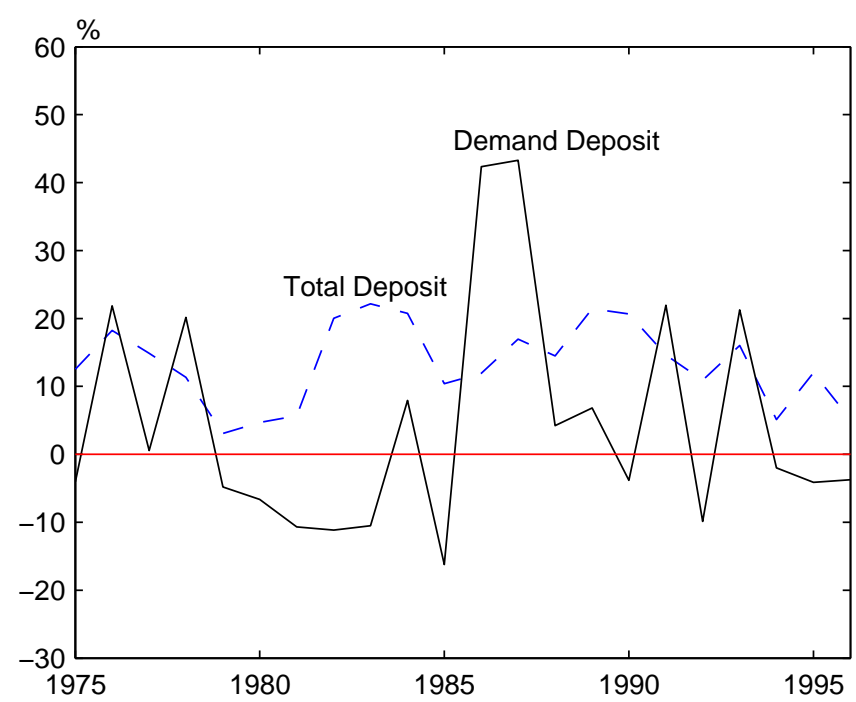

Figure 4. Use of Savings

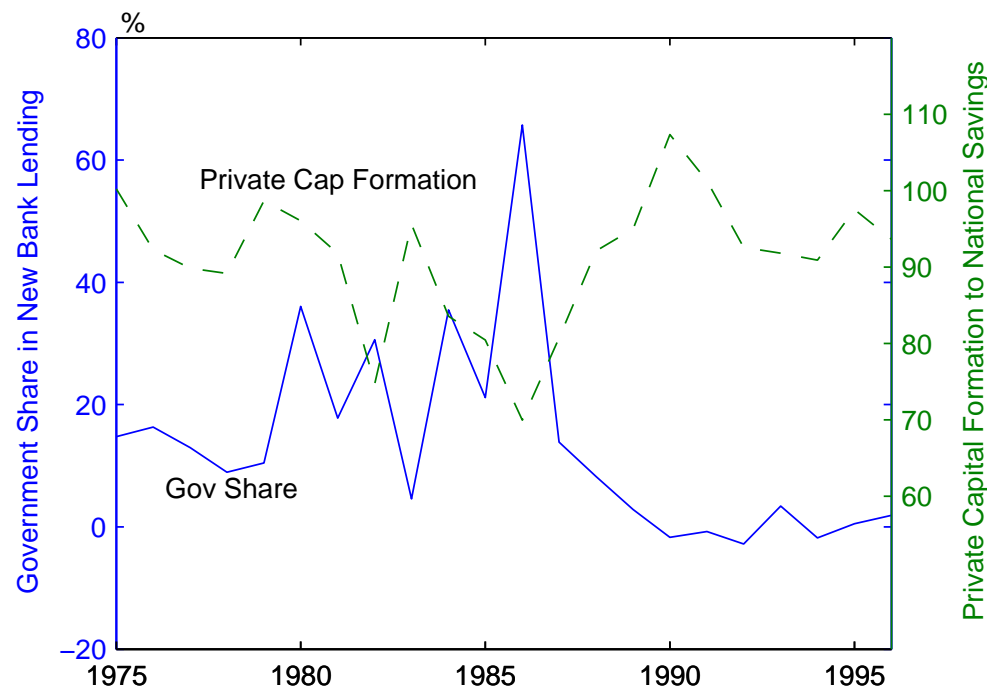


Figure 5. Value Functions

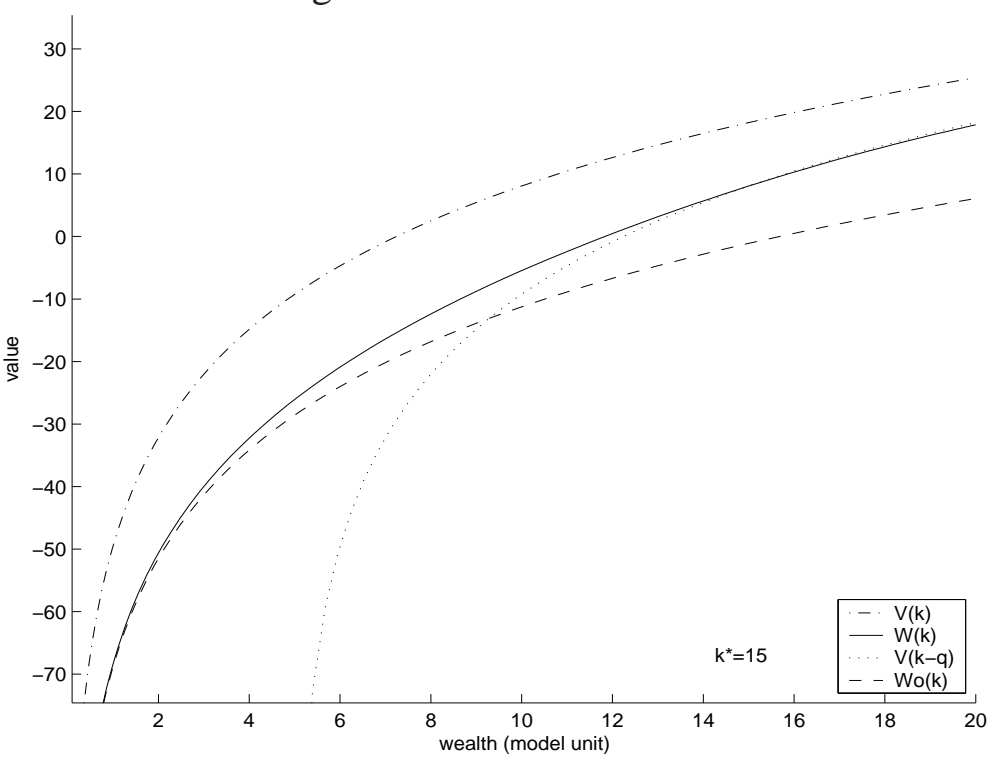

Figure 6. Policy Functions
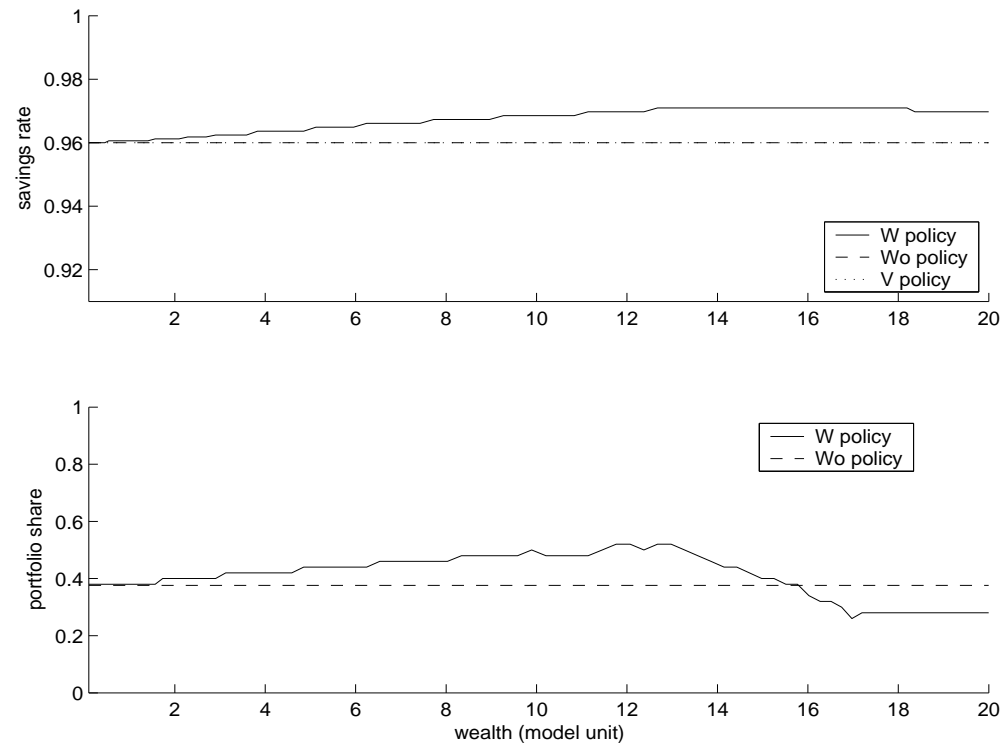
Figure 7. Benchmark
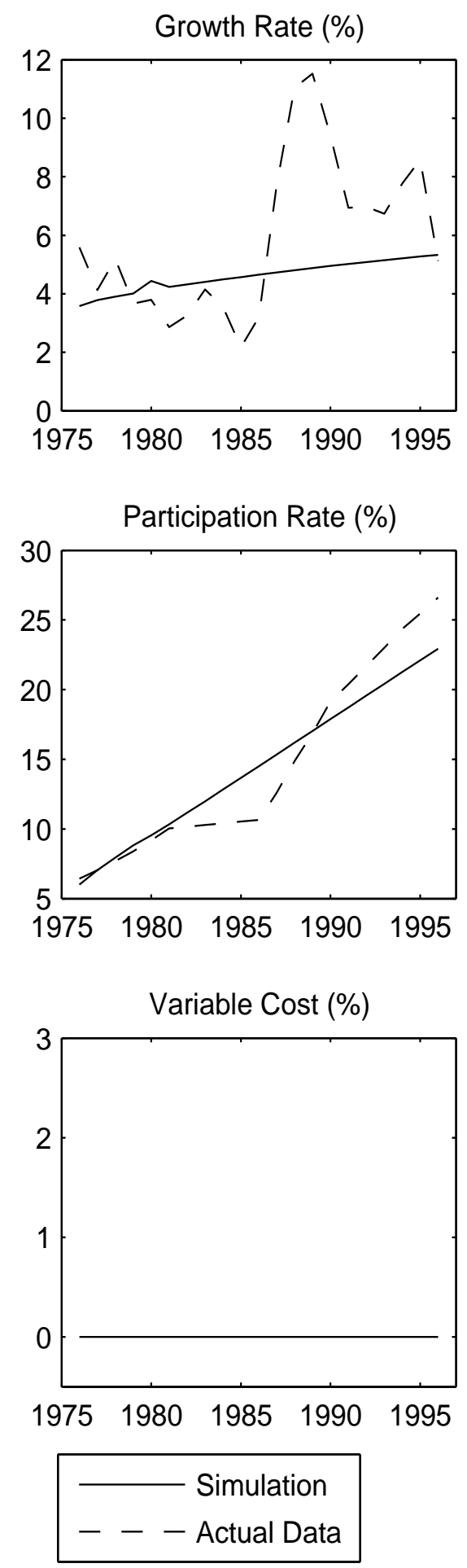

Figure 8. Actual Shocks
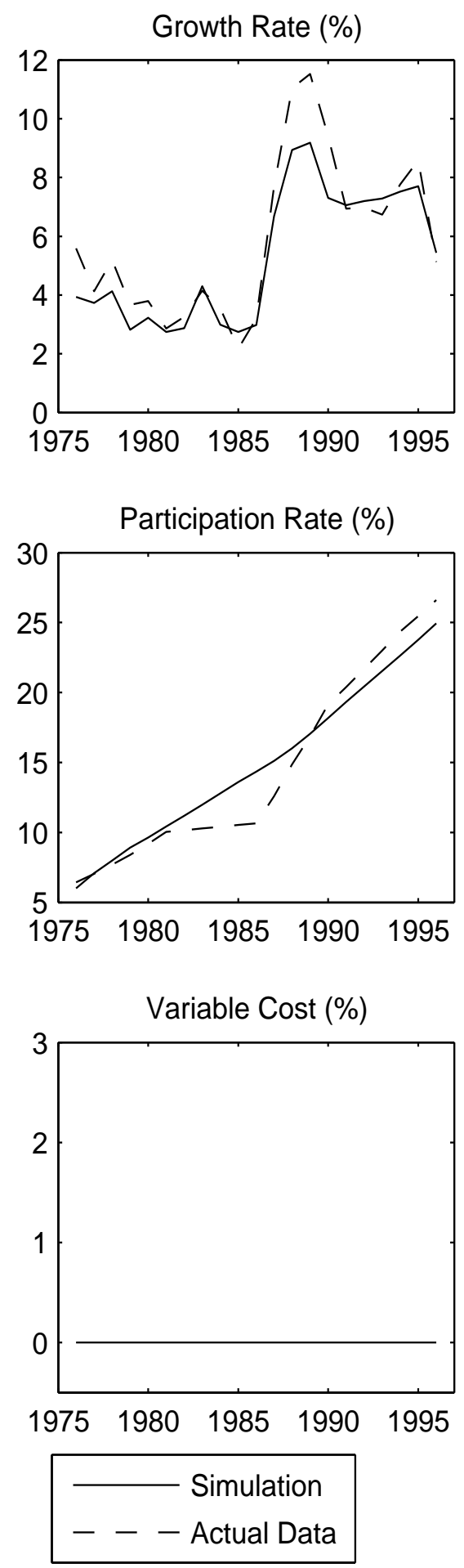
Figure 9. Changing Variable Costs

Figure 10. Changing Entry Costs
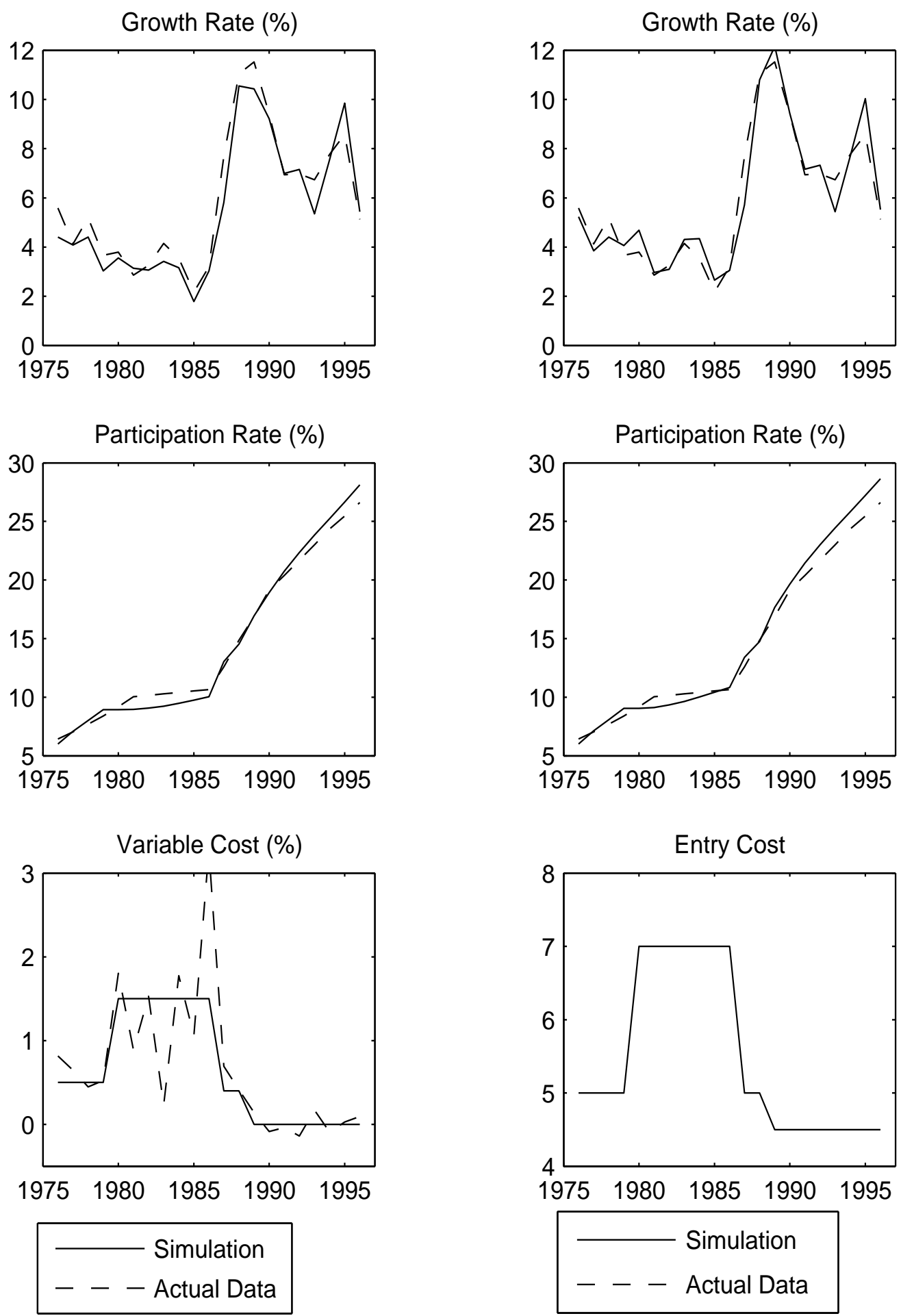
Figure 11. Lower Safe Return, Var Cost
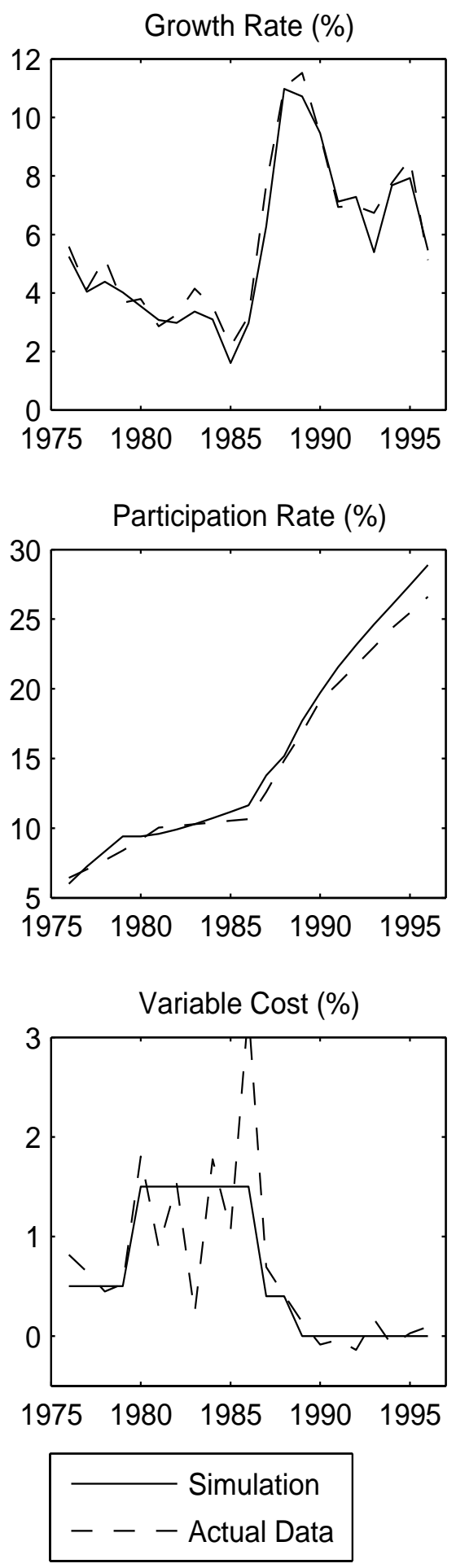

Figure 12. Lower Safe Return, Ent Cost
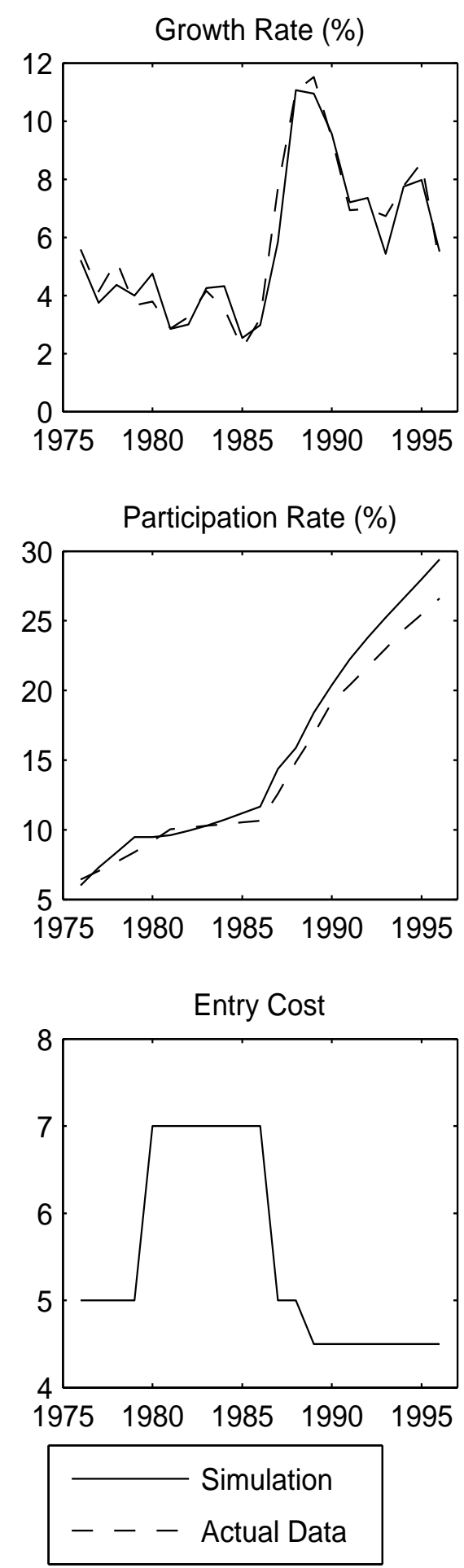
Figure 13. Higher Risk Aversion, Var Cost Figure 14. Higher Risk Aversion, Ent Cost
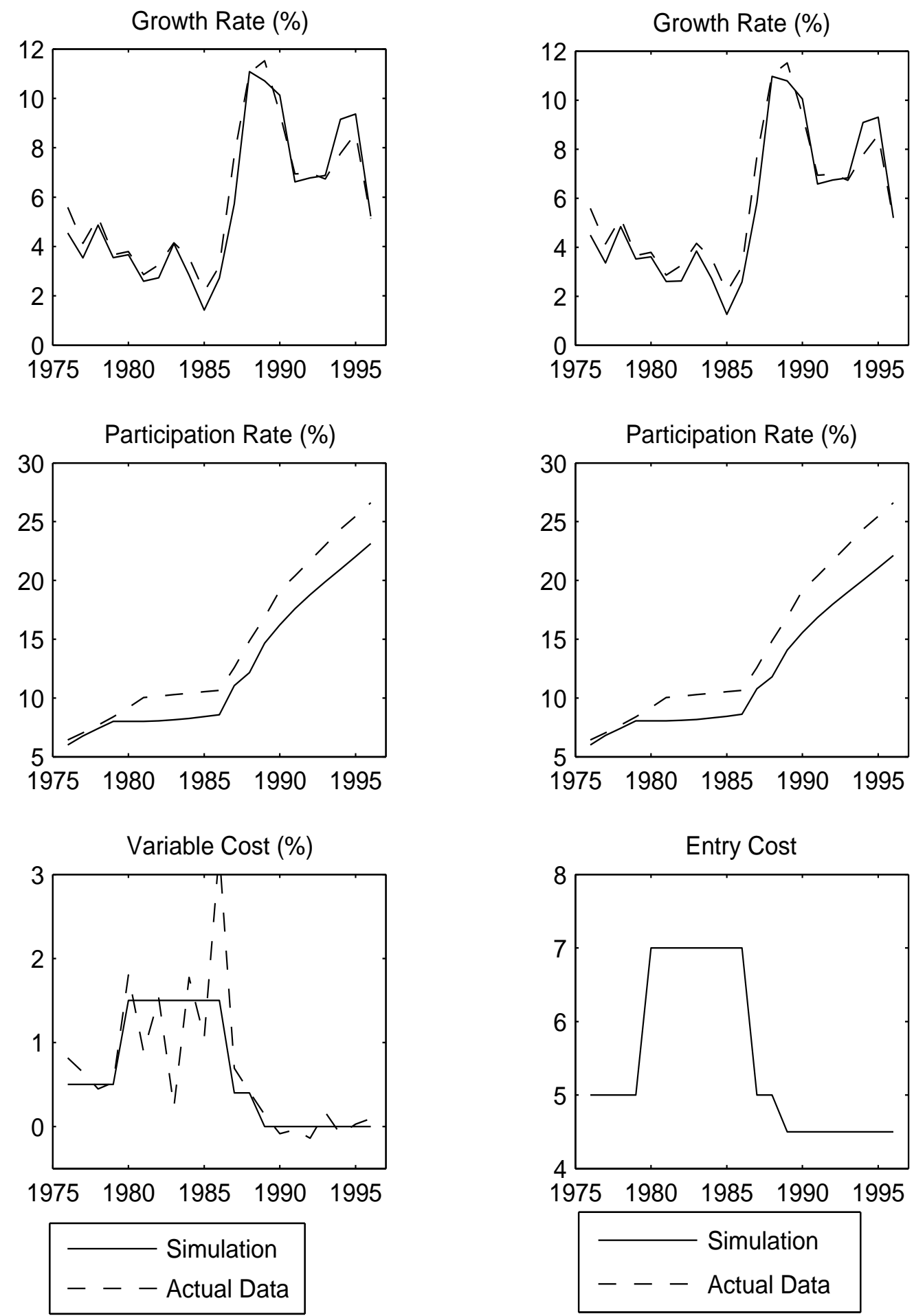
Figure 15. Welfare Gains from Eliminating 1.5\% Variable Cost
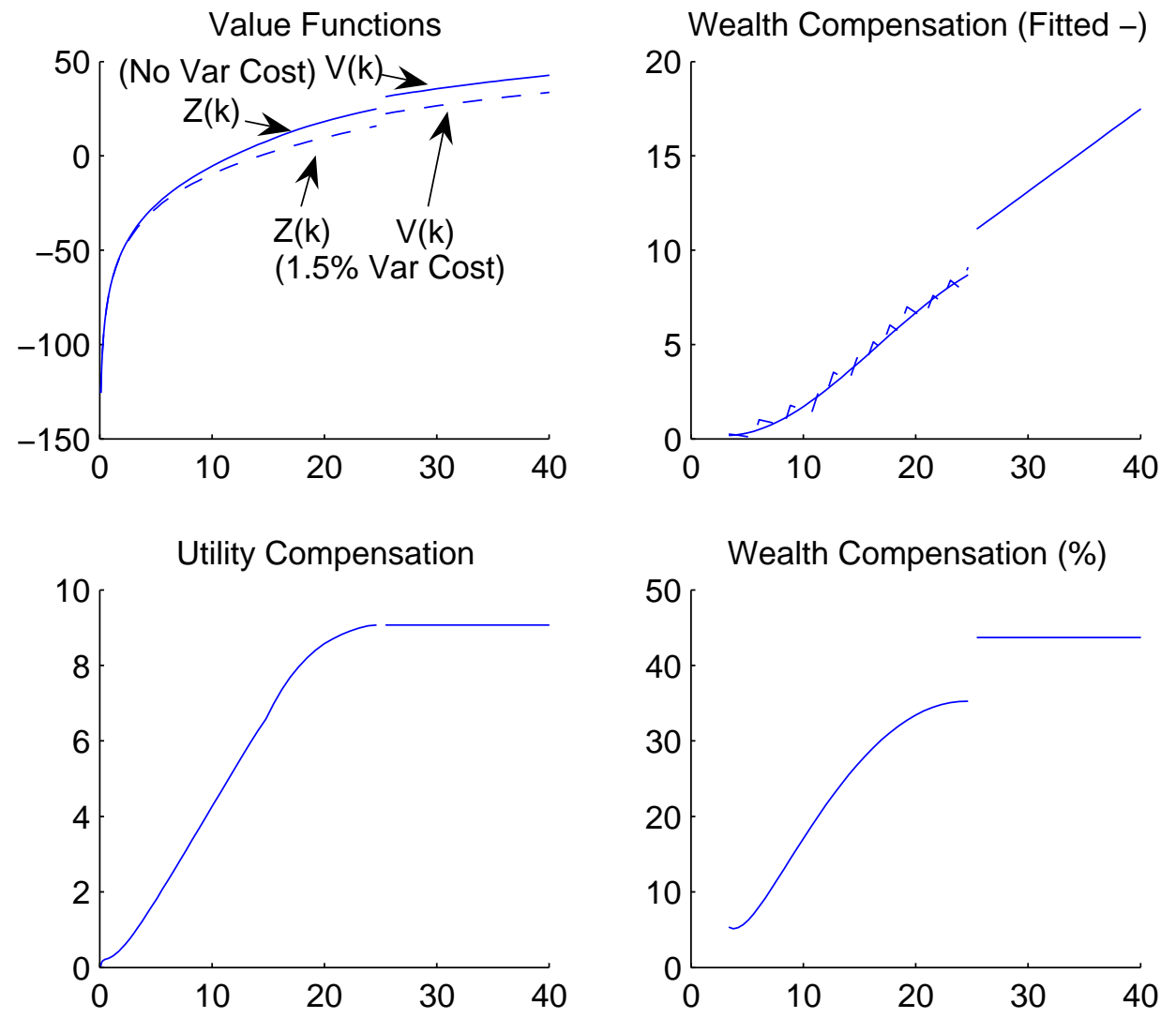
Figure 16. Welfare Gains from Reduction in Entry Cost (7 to 4.5)
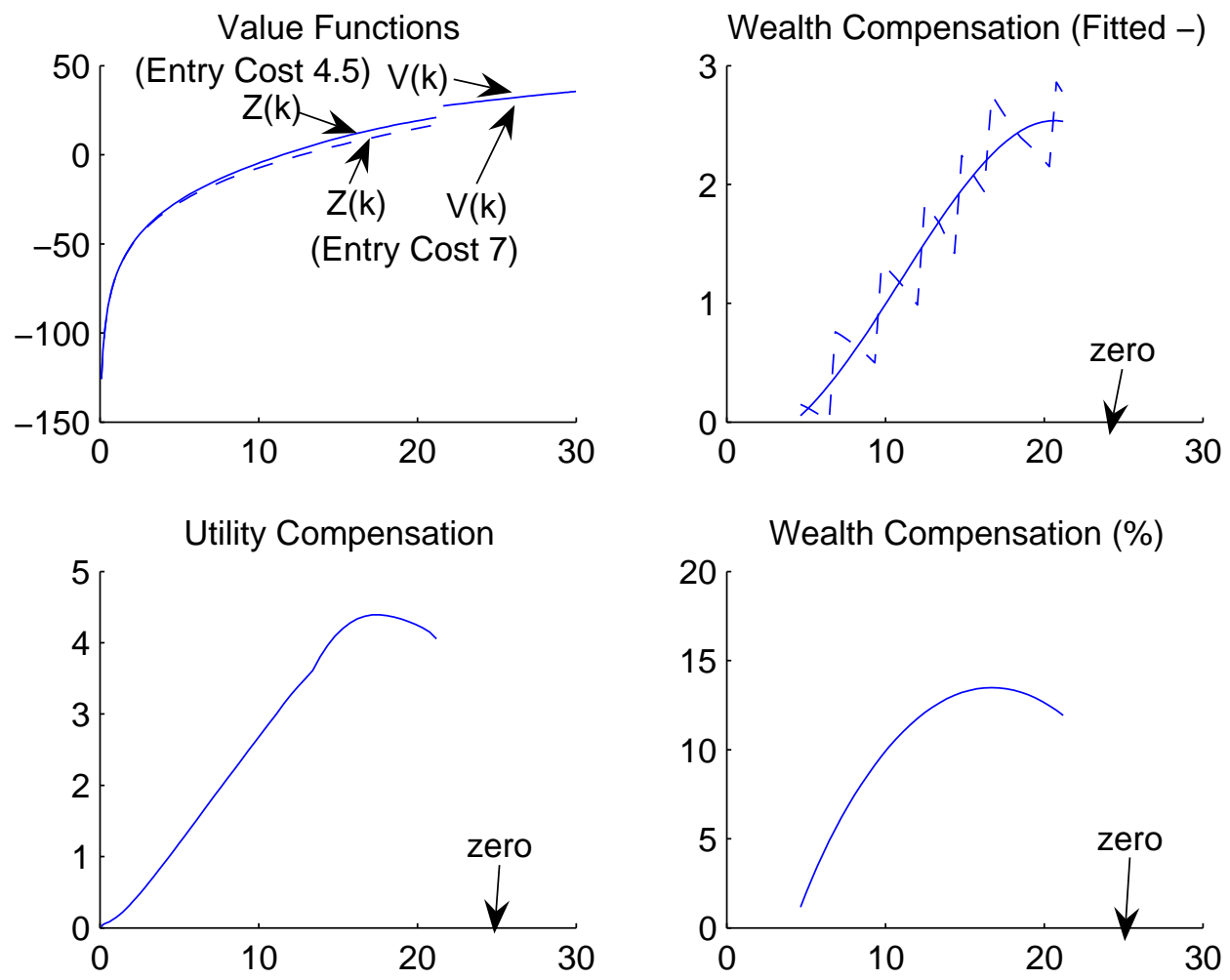
Figure 17. On-Off Welfare Gains
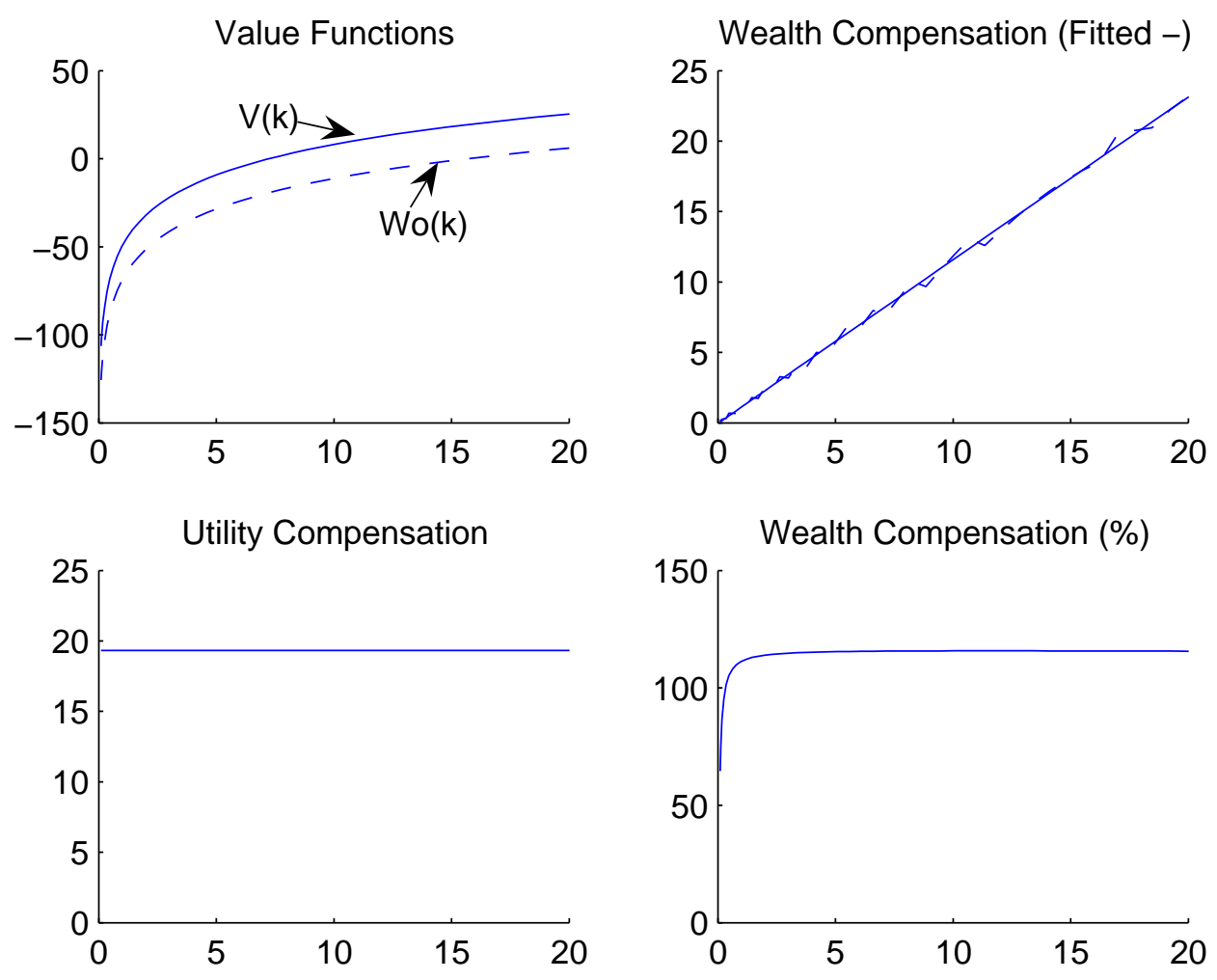
Table 2. Growth Difference (\%)

\begin{tabular}{|c|c|c|c|}
\hline & $\begin{array}{c}1987-96 \\
\text { Growth } \\
\text { Difference }\end{array}$ & $\begin{array}{c}\text { Annualized } \\
\text { Growth with } \\
\text { Cost Reduction }\end{array}$ & $\begin{array}{c}\text { Annualized } \\
\text { Growth without } \\
\text { Cost Reduction }\end{array}$ \\
\hline $\begin{array}{l}\text { Variable Cost Reduction } \\
\text { in } 1987(1.5 \% \text { to } 0 \%)\end{array}$ & $\begin{array}{c}0.59 \\
{[0.96]}\end{array}$ & $\begin{array}{c}6.87 \\
{[4.41]}\end{array}$ & $\begin{array}{l}6.28 \\
{[3.45]}\end{array}$ \\
\hline $\begin{array}{l}\text { Entry Cost Reduction } \\
\text { in } 1987 \text { ( } 7 \text { to } 4.5 \text { model unit) }\end{array}$ & $\begin{array}{l}-0.14 \\
{[-0.26]}\end{array}$ & $\begin{array}{c}7.34 \\
{[4.48]}\end{array}$ & $\begin{array}{c}7.48 \\
{[4.74]}\end{array}$ \\
\hline
\end{tabular}

Note: Iterated shocks are used in the simulation. Numbers in brackets are results of alternative simulation using the expected value of shocks after 1987.

Table 3. Welfare Gains

\begin{tabular}{lccc}
\hline & $\begin{array}{c}\text { Welfare Gains } \\
\text { (\% income) }\end{array}$ & $\begin{array}{c}\text { Nonparticipants } \\
\text { (population) } \\
\text { [income share] }\end{array}$ & $\begin{array}{c}\text { Participants } \\
\text { (population) } \\
\text { [income share] }\end{array}$ \\
\hline $\begin{array}{l}\text { Variable Cost Reduction } \\
\text { in 1987 (1.5\% to 0\%) }\end{array}$ & 27.1 & 14.2 & 43.7 \\
& & $(88.9)$ & $(11.1)$ \\
Entry Cost Reduction & {$[56.3]$} & {$[43.7]$} \\
in 1987 (7 to 4.5 model unit) & 2.0 & 3.9 & 0.0 \\
& & $(88.0)$ & $(12.0)$ \\
& & {$[51.6]$} & {$[48.4]$} \\
\hline
\end{tabular}


Table 4. Sensitivity Analysis: Variable Cost Reduction

\begin{tabular}{lccc}
\hline & $\begin{array}{c}\text { Benchmark } \\
\text { Case }\end{array}$ & $\begin{array}{c}\text { Lower Safe } \\
\text { Return } \\
(\delta=1.047)\end{array}$ & $\begin{array}{c}\text { Higher Risk } \\
\text { Aversion } \\
(\sigma=1.5)\end{array}$ \\
\hline $\begin{array}{l}\text { Growth Difference (\%) } \\
\text { [with mean shocks after 1987] }\end{array}$ & 0.59 & 0.62 & 0.67 \\
Welfare Gains (\% income) & {$[0.96]$} & {$[1.06]$} & {$[-0.32]$} \\
(Nonparticipants) & 27.1 & 27.9 & 18.0 \\
[Participants] & $(14.2)$ & $(12.9)$ & $(8.6)$ \\
Participation Rate at 1987 (\%) & {$[43.7]$} & {$[43.7]$} & {$[30.4]$} \\
Average Magnitude of Agg. Shocks $(\%)$ & 11.1 & 12.9 & 9.3 \\
\end{tabular}

Note: Definition of growth difference and welfare gains are the same as in Table 2 and 3, respectively. All simulations use the same policy changes in the variable cost as in the benchmark case. Iterated shocks are used, but tailored to each simulation to mimic the actual GDP growth rate. The average magnitude of those shocks are reported in the last row.

Table 5. Sensitivity Analysis: Entry Cost Reduction

\begin{tabular}{lccc}
\hline & $\begin{array}{c}\text { Benchmark } \\
\text { Case }\end{array}$ & $\begin{array}{c}\text { Lower Safe } \\
\text { Return } \\
(\delta=1.047)\end{array}$ & $\begin{array}{c}\text { Higher Risk } \\
\text { Aversion } \\
(\sigma=1.5)\end{array}$ \\
\hline $\begin{array}{l}\text { Growth Difference (\%) } \\
\text { [with mean shocks after 1987] }\end{array}$ & -0.14 & -0.17 & -0.04 \\
& {$[-0.26]$} & {$[-0.24]$} & {$[-0.36]$} \\
Welfare Gains (\% income) & 2.0 & 2.1 & 1.1 \\
$\begin{array}{l}\text { (Nonparticipants) } \\
\text { [Participants] }\end{array}$ & $(3.9)$ & $(4.2)$ & $(2.0)$ \\
Participation Rate at 1987 (\%) & {$[0.0]$} & {$[0.0]$} & {$[0.0]$} \\
Average Magnitude of Agg. Shocks (\%) & 0.75 & 13.0 & 9.3 \\
& & 0.74 & 3.55 \\
\hline
\end{tabular}

Note: Definition of growth difference and welfare gains are the same as in Table 2 and 3, respectively. All simulations use the same policy changes in the entry cost as in the benchmark case. IIterated shocks are used, but tailored to each simulation to mimic the actual GDP growth rate. The average magnitude of those shocks are reported in the last row. 


\section{Appendix I. Closed-Form Solutions of Welfare Gains for Participants}

We are interested in finding $\tau$ that satisfies $\hat{V}(k)=V(k+\tau)$. Under the reduced variable cost, the return would be higher, and let $\Delta$ denote the difference of expected log return. Using the definition of the value function (14), we can find a closed-form expression for $\tau$.

$$
\begin{aligned}
\hat{V}(k) & =\frac{1}{1-\beta} \ln (1-\beta)+\frac{\beta}{(1-\beta)^{2}} \ln \beta+\frac{\beta}{(1-\beta)^{2}}(E \ln r(\theta)+\Delta)+\frac{1}{1-\beta} \ln k, \\
& =\frac{1}{1-\beta} \ln (1-\beta)+\frac{\beta}{(1-\beta)^{2}} \ln \beta+\frac{\beta}{(1-\beta)^{2}} E \ln r(\theta)+\frac{1}{1-\beta}\left(\ln k+\frac{\beta \Delta}{1-\beta}\right), \\
& =\frac{1}{1-\beta} \ln (1-\beta)+\frac{\beta}{(1-\beta)^{2}} \ln \beta+\frac{\beta}{(1-\beta)^{2}} E \ln r(\theta)+\frac{1}{1-\beta}\left(\ln k \exp \left[\frac{\beta \Delta}{1-\beta}\right]\right) .
\end{aligned}
$$

Therefore,

$$
\tau=\left(\exp \left[\frac{\beta \Delta}{1-\beta}\right]-1\right) k
$$

Similarly, for the case with CRRA utility, we can also find a closed-form expression for $\tau$. Note that the participant's value function is simply $V(k)=\left(1-\mu^{*}\right)^{-\sigma} k^{1-\sigma} /(1-\sigma)$, where $\mu^{*}$ is the optimal savings rate and equals $\left\{\beta E\left[r(\theta)^{1-\sigma}\right]\right\}^{1 / \sigma} .^{57}$ Let $\Delta$ denote the difference in the log propensity to consume under the reduced cost regime. ${ }^{58}$

$$
\begin{aligned}
\ln \hat{V}(k) & =-\sigma\left(\ln \left(1-\mu^{*}\right)+\Delta\right)+(1-\sigma) \ln k-(1-\sigma), \\
& =-\sigma \ln \left(1-\mu^{*}\right)+(1-\sigma)\left(\ln k+\frac{\sigma \Delta}{\sigma-1}\right)-(1-\sigma), \\
& =-\sigma \ln \left(1-\mu^{*}\right)+(1-\sigma)\left(\ln k \exp \left[\frac{\sigma \Delta}{\sigma-1}\right]\right)-(1-\sigma) .
\end{aligned}
$$

Therefore,

$$
\tau=\left(\exp \left[\frac{\sigma \Delta}{\sigma-1}\right]-1\right) k
$$

Note that in both log and general CRRA utility cases, the welfare gains for participants from reduction in the variable cost are constant fraction of the wealth.

\footnotetext{
${ }^{57}$ See the derivation of the participant's value function $V(k)$ in Townsend and Ueda (2006).

${ }^{58}$ Note that the size of $\Delta$ is a nontrivial function of a change in return $r(\theta)$ but we can obtain it numerically.
} 